\title{
WestVirginiaUniversity
}

THE RESEARCH REPOSITORY @ WVU

Graduate Theses, Dissertations, and Problem Reports

2010

\section{Parenting practices mediate parenting stress and child inhibited, shy behavior}

\author{
Ying Dong \\ West Virginia University
}

Follow this and additional works at: https://researchrepository.wvu.edu/etd

\section{Recommended Citation}

Dong, Ying, "Parenting practices mediate parenting stress and child inhibited, shy behavior" (2010). Graduate Theses, Dissertations, and Problem Reports. 4580.

https://researchrepository.wvu.edu/etd/4580

This Thesis is protected by copyright and/or related rights. It has been brought to you by the The Research Repository @ WVU with permission from the rights-holder(s). You are free to use this Thesis in any way that is permitted by the copyright and related rights legislation that applies to your use. For other uses you must obtain permission from the rights-holder(s) directly, unless additional rights are indicated by a Creative Commons license in the record and/ or on the work itself. This Thesis has been accepted for inclusion in WVU Graduate Theses, Dissertations, and Problem Reports collection by an authorized administrator of The Research Repository @ WVU. For more information, please contact researchrepository@mail.wvu.edu. 


\title{
PARENTING PRACTICES MEDIATE \\ PARENTING STRESS AND CHILD INHIBITED, SHY BEHAVIOR
}

Ying Dong

\author{
Thesis Submitted to \\ The College of Human Resources and Education \\ at West Virginia University \\ in partial fulfillment of the requirements for the degree of \\ Master of Arts \\ In Educational Psychology \\ With an emphasis in Child Development and Family Studies
}

Amy E. Root, Ph.D., Committee Chair

Kristin Moilanen, Ph.D., Member

Jessica Troilo, Ph.D., Member

Department of Technology, Learning, and Culture

Morgantown, West Virginia

2010

Keywords: Parenting Stress; Parenting Practices; Inhibited/Shy Behavior

Copyright 2010 Ying Dong 


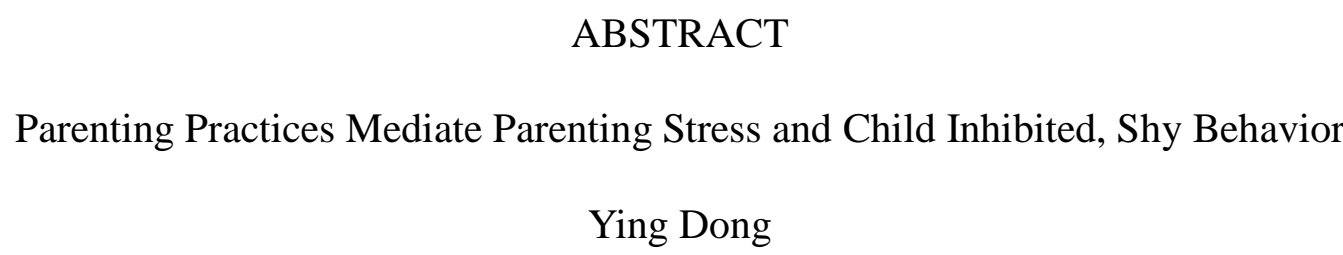

Parenting practices were investigated as mediators between parenting stress and child inhibited, shy behavior. Parenting stress was also examined as a moderator between parenting practices and child inhibited, shy behavior. Twenty-seven preschool-aged children (14 boys, 13 girls; mean age $=3.5$ years) and their mothers (mean age $=34$ years) participated in the study. Mothers completed a battery of questionnaires to assess parenting stress, parenting practices, and child inhibited, shy behavior. Regression analyses were conducted and it was found that parenting practices do not mediate the relation between parenting stress and inhibited, shy behavior. However, there appears to be an indirect relation between parenting stress, authoritarian parenting, and inhibited, shy behavior; a similar association was found for the models with authoritative parenting. Moreover, parenting stress appears to exacerbate the relation between overprotective parenting and inhibited, shy behavior. The findings of this study provide an understanding of how parents may develop dysfunctional parenting practices via parenting stress, and the implications of parenting stress on the development of inhibited, shy behavior. 


\section{ACKNOWLEDGEMENTS}

I sincerely appreciate all of my committee members' instructions and encouragement that supported the completion of my thesis. Especially, my advisor, Dr. Amy Root, has kept me on the right track and introduced me to the research world. I also would like to thank Dr. Kristin Moilanen, for her meticulous and thoughtful suggestions which reminded me to do research

precisely. In addition, I am thankful to Dr. Jessica Troilo's suggestions which helped me look at different, interesting ideas for my study. Here, I think all my words appear insufficient in expressing my thanks for all my learning from you. Again, without all your supports, it would be impossible for me to complete my thesis as smoothly as possibly and as quickly as possible.

Of course, I appreciate my husband, Guoxiang Liu’s love, understanding, patient, and supporting that have encouraged me to pursue a higher level of study. Absolutely, I also appreciate my mother, my father and my old brother who have provided me generous helps physically and psychologically during my study. 


\section{TABLE OF CONTENTS}



Acknowledgments.................................................................



List of Tables..................................................................

List of Figures........................................................... vii

\section{Chapter 1: Introduction}

Overview......................................................1

Problem Statement.................................................2

Purpose....................................................................

\section{Chapter 2: Literature Review}

Overview.......................................................4

The Development of Behavioral Inhibition...............................5

Parenting........................................................ 5

Parenting Stress and Dysfunctional Parenting.............................14

The Definition of Parenting Stress.......................................15

Parenting Stress Index (PSI)..................................... 16

Parenting Stress, Poor Parenting and Child Development...................16

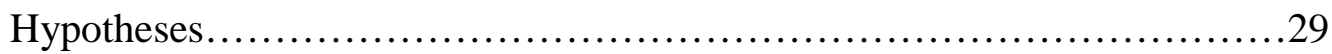

\section{Chapter 3: Method}

Participants.................................................... 31



Recruitment of Sample..................................................31

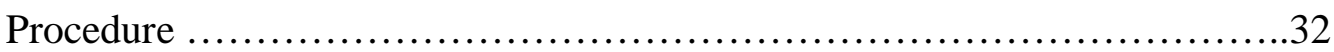

Instrumentation....................................................32

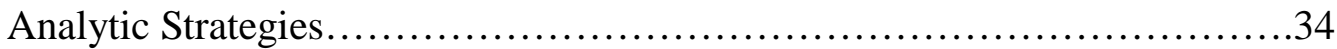

\section{Chapter 4: Results}

Mediation Models...................................................... 36 


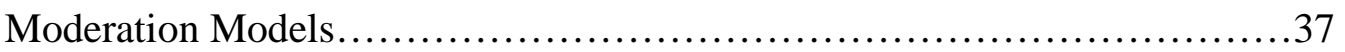

Predictions of Inhibition, Shy Behavior.................................38

\section{Chapter 5: Discussion}

Parenting Practices as Mediators.....................................40

Parenting Stress as a Moderator.........................................43

The Role of Parenting Stress in the Development of Inhibited, Shy

Behavior.......................................................43

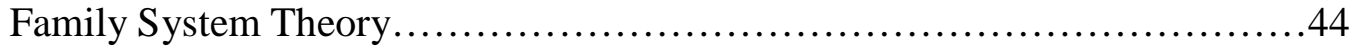

Limitations and Future Directions.....................................46

Conclusions......................................................49

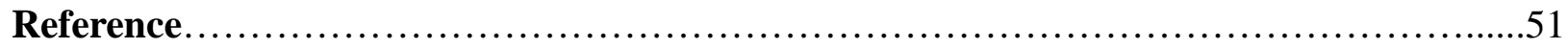

Appendices

Appendix A: Demographic Information.......................................73

Appendix B: Parenting Stress Index/ Short Form..............................78

Appendix C: Parenting Practices Questionnaire....................................82

Appendix D: Children’s Behavior Questionnaire /Short Form Version 1..............86

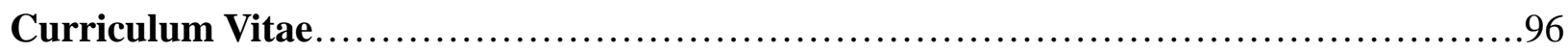




\section{List of Tables}

Table 1- Means and Standard Deviations of Independent Variables and Dependent

Variables......................................................................61

Table 2- Correlations Between Independent \& Dependent Variables........................62

Table 3- Mediation Analyses....................................................63

Table 4- Moderation Models....................................................64 


\section{List of Figures}

Figure 1- Model of Theorized Paths of Influence on Parenting Behaviors and Child Outcomes...............65

Figure 2- The Theorized Paths of Influence Regarding the Determinants of Parenting Behavior

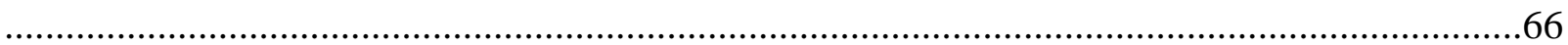

Figure 3- The Process Model of the Determinants of Parenting ............................................67

Figure 4- Theoretical Mediation Model..........................................................................68



Figure 6- Tested Model 2......................................................... 70



Figure 8- Inhibited, Shy Behavior as a Function of Overprotective Parenting at Levels of

Parenting Stress............................................................. 72 


\section{CHAPTER 1 \\ INTRODUCTION}

\section{Overview}

Behavioral inhibition (BI) is the dispositional tendency to display fearful behavior in the face of novel stimuli (Kagan, Reznick, Clarke, Snidman, \& Garcia-Coll, 1984). Inhibited children demonstrate low temperamental approach, and have been characterized by their disposition to display wary and fearful behavior in unfamiliar contexts (Kagan et al., 1984; Rubin \& Asendorpf, 1993), as well as in-school social inhibition (Scarpa, Raine, Venables, \& Mednick, 1997). Children’s behavioral inhibition has been associated with a host of socio-emotional difficulties, including social phobic disorders (Biederman et al., 1993), depression and social anxiety (Muris, Merckelbach, Schmidt, Gadet, \& Bogel, 2001). Moreover, social withdrawal (an outcome associated with behavioral inhibition) has been associated with a wide range of indices of psychosocial maladjustment including anxiety (Coplan, Prakash, O’Neil, \& Armer, 2004), internalizing difficulties (Rubin, Chen, McDougal, Bowker, \& McKinnon, 1995), and interpersonal incompetence (Rubin, Daniels-Bierness, \& Bream, 1984).

Importantly, behavioral inhibition is thought to be moderately stable (Kagan, Snidman, Kahn, \& Towsley, 2007) and a large number of empirical studies have indicated that trajectories of behavioral inhibition can be moderated by environmental factors, including parenting practices (e.g., LaFreniere \& Dumas, 1992; Park, Belsky, Putnam, \& Cronic, 1997; Rubin, Hastings, Stewart, Henderson, \& Chen, 1997; Rubin, Burgess, \& Hastings, 2002; Shamir-Essakow, Ungerer, \& Rapee, 2004). Specifically, parenting characterized as warm, responsive, and sensitive is thought to reduce or change children's behavioral inhibition (Early et 
al., 2002). On the other hand, dysfunctional parenting, such as overprotective or authoritarian parenting (e.g. LaFreniere \& Dumas, 1992; Mills \& Rubin, 1990; Rubin et al., 1997) may promote or maintain children's behavioral inhibition.

Although the associations between parenting and behavioral inhibition are well-established, it leads to the question: Why do some parents engage in adaptive parenting practices such as warm, supportive, sensitive or responsive parenting that reduce the children's inhibited and shy behavior and others engage in dysfunctional parenting practices, such as intrusive, non-sensitive, or controlling parenting practices that exacerbate the children's behavioral inhibition?

Empirical research suggests that parenting stress may lead to impairments in the parenting process. Indeed, parents with high levels of stress have been shown to be less responsive (Gelfand, Teti, \& Fox, 1992), more authoritarian (Deater-Deckard, 1996), more punitive (Guajardo, Snyder, \& Petersen, 2009), more power assertive (Mills \& Rubin, 1990), more neglectful (Assel, Swank, Steelman, Miller-Loncar, \& Smith, 2002), more harsh (Erath, El-Sheikh, \& Cummings, 2009), and, in extreme cases, abusive (Chan, 1994; Holden \& Banez, 1996) when compared to parents with lower levels of stress. In turn dysfunctional parenting practices associated with stress negatively impacts children's development and has been associated with internalizing and externalizing difficulties (Conger, Guajardo, Snyder, \& Petersen, 2009; Conger, Patterson, \& Ge, 1995; Feldman, Eidelman, \& Rotenberg, 2004).

\section{Problem Statement}

Thus, it may be that parenting stress is one of the contributors to parents' maladaptive parenting practices, however little is known about the relation between parenting stress and the development of behavioral inhibition. In fact, after an extensive search of the literature, it 
appears that only one published study (Mills \& Rubin, 1990) examined the relation among parenting stress, dysfunctional parenting practices, and parental beliefs toward children's social withdrawal behavior. They found that mothers with high levels of stress (low occupational status, low level social support and/high negative emotions) were more likely to engage in highly power assertive socialization behavior and strategies toward their children's display of social withdrawal; thereby indicating that parenting stress might affect the parents of shy, wary children. However, Mills and Rubin (1990) did not further examine how parenting stress may contribute to the development of inhibited, shy behavior.

\section{Purpose}

In the proposed study, I examined the contribution of parenting stress to the development of inhibited, shy behavior. Specifically, a mediation model was developed to test the link between parenting stress, parenting practices, and children’s inhibited, shy behavior. The findings drawn from the current study will provide evidence for the development of intervention techniques aimed at the parents of inhibited, shy children. 


\section{CHAPTER 2}

\section{LITERATURE REVIEW}

\section{Overview}

It is important for children to be able to interact with peers. As suggested by Mead (1934), “Exchanges between peers, whether experienced in the arenas of cooperation or competition, conflict or friendship, allow children to gain an understanding of both self and others” (as cited by Rubin \& Asendorpf, 1993, p. 7). Indeed it has long been suggested that social interaction is critical for cognitive development (e.g., Piaget, 1928), perspective taking skills (Chandler, 1973), and the development of emotional competence (Denham, Bassett, \& Wyatt, 2007). Thus, it should not be surprising that children who refrain from social interaction with peers have been the attention of psychologists and developmental researchers (e.g., Rubin \& Asendorpf, 1993).

Many researchers have concentrated their efforts to understand the development of children classified as behaviorally inhibited, or the disposition to be fearful in the face of novelty (Kagan et al., 1984) because inhibited infants often grow into shy, wary preschoolers (e.g., Rubin, Hastings, \& Burgess, 2002). Accordingly, these children have fewer opportunities to engage in peer interaction, which may impact future development.

Indeed, it appears that behavioral inhibition may be a precursor for the development of social withdrawal (the consistent - across time and situations - display of solitary behavior when encountering familiar and/or unfamiliar peers; Rubin, Bowker, \& Kennedy, 2009), which has been associated with the dysregulation of negative affect (Rubin, Coplan, Fox, \& Calkins, 1995); social incompetence and peer rejection (Gazelle, 2003; Rubin, Daniels-Bierness, \& Bream, 1984); and anxiety and depression (Bell-Dolan, Reaven, \& Peterson, 1993). Moreover, it is 
evident from research conducted in the US and Canada that when children are more inhibited and socially withdrawn, they are less socially competent and less popular among peers than uninhibited children (e.g., Gazelle, 2006; Gazelle \& Spangler, 2007), and more likely to become depressed adults (Caspi, Moffit, Newman, \& Silva,1996). Thus it seems critical to better understand the antecedents of shy, wary behavior in order to prevent or intervene in the development of behavioral inhibition.

\section{The Development of Behavioral Inhibition}

Behavioral inhibition has been examined by researchers for nearly three decades (e.g., Fox \& Calkins, 1993; Kagan et al., 1984; Mills \& Rubin, 1990). As aforementioned, behavioral inhibition (BI) is the dispositional tendency to display fearful behavior in the face of novel stimuli (Kagan, Reznick, Clarke, \& Snidman, 1987). Inhibited children demonstrate low temperamental approach, and have been characterized by their disposition to display wary and fearful behavior in unfamiliar contexts (Rubin \& Asendorpf, 1993), as well as in-school social inhibition (Scarpa, Raine, Venables, \& Mednick, 1997). Behavioral inhibition is thought to be moderately stable (Kagan, Snidman, Kahn, \& Towsley, 2007), and researchers have worked to uncover which environmental factors may contribute to the stability of behavioral inhibition. A child's caregiving environment has been shown to play a significant role in the stability of behavioral inhibition (e.g., LaFereniere \& Dumas, 1992; Park et al., 1997; Rubin, Nelson, Hastings, \& Asendorpf, 1999; Shamir-Essakow et al., 2004). Therefore, I will next discuss the role of parents in the development of children's behavioral inhibition.

\section{Parenting}

In order to make sense how family factors may have influenced the development of behavioral inhibition, the relation between behavioral inhibition and parenting has increasingly 
become the focus of several research groups (e.g., Rubin et al., 1997). It has been proposed that parents' interactions with their children may enhance or reduce behavioral inhibition (e.g., LaFreniere \& Dumas, 1992; Park et al., 1997; Rubin et al., 1997; Rubin et al., 1999; Rubin et al., 2002; Shamir-Essakow et al, 2004). Overprotective parenting, for one, has been implicated in the exacerbation of inhibited temperament. Overprotection refers to the encouragement of dependency, intrusive behavior, and controlling children’s behavior (Rubin et al., 2002). Overprotective parents often overly intrude and enmesh with their children without leaving them freedom to explore (Rubin et al., 1997). Thus, overprotective parenting may prevent children from practicing necessary self-initiated coping skills and autonomous behavior (Rubin et al., 2002).

There is empirical support for the role of overprotective parenting in the development of behavioral inhibition. For example, Rubin, Hastings, Stewart, Henderson and Chen (1997) tested the association between toddler inhibition and parenting behavior. They found that children were more likely to demonstrate inhibited behavior if their mothers behaved in a highly directive and intrusive fashion during a free play situation. In this longitudinal study, 108 toddlers and their mothers participated in an adapted version of the Behavioral Inhibition Paradigm (e.g., Garcia Coll et al., 1984), which was used to measure children’s behavioral inhibition. First, the mother and child entered an unfamiliar room in which the mother filled out a questionnaire (free play 1) and the child played with toys for ten minutes. Next, the experimenter asked the child to tidy up the toys (clean-up). Then, an unfamiliar woman entered room with a toy dump truck and some blocks. She quietly played one minute and invited the child to play with her if the child still did not approach her. After three minutes, she left and returned with a toy robot that moved and emitted smoke. The woman said nothing for 30 
seconds, and invited the child to play with robot for one minute and left. The third time she entered the room; she brought an inflatable tunnel and encouraged the child to crawl through. After she left, a third woman who met with the child when the child came to the lab entered into the room dressed as a clown. The clown kept silent for 30 seconds and invited the child to approach her for one minute. Then, the clown removed the costume and reminded the child that she had met her before. During the second laboratory session, participants engaged in a peer-play, where they encountered an unfamiliar same age, same sex child. During these tasks, children's shy, wary behaviors were coded and mothers' parenting was coded too. The results indicated that toddlers who were inhibited in both strange adult and peer context were more likely to be fearful and distressed when separated from their mothers. Further, mothers of inhibited children were more likely to engage in oversolicitious (intrusive, controlling, and inappropriately warm) parenting behaviors. In other words, mothers of inhibited children were warm and highly enmeshed but they were not responsive to their children's cues and insensitive to their children's needs. It might be children's temperament leads to parental controlling or intrusive behavior. Better put parents of inhibited/shy children believe that their children will behave incompetently in an unfamiliar setting; thus these parents may feel that they need to give more direction to their children, as evidenced in the findings presented above. However, mothers' intrusiveness may result in further detriment to their children’s behavioral inhibition because they prevent their children from "practicing necessary coping skills, overcoming the dispositional wariness, and developing self-efficacy” (Rubin et al., 1997, p. 480). In addition, parents' intrusive behavior might decrease children's self-confidence and increase children's dependence. The reasons might be that when parents of inhibited/shy children always tell their children what they need to do, their children gradually suspect they are incompetent to 
independently decide their own behavior; as a result they might feel inferior and become dependent on their parents to make decisions for them.

In order to better understand the relations between behavioral inhibition and parenting, it seems necessary to examine the perceptions/beliefs parents have toward their children’s inhibited/shy behavior; as these beliefs may provide a better understanding why some parents engage in overprotective practices. Rubin, Nelson, Hastings, and Asendorpf (1999) further examined the association of between parental beliefs about children's inhibited, shy behavior and later parental socialization strategies. In this study, they reported that mothers of children who were behaviorally inhibited were more likely to describe their children as shy and anxious than mothers of uninhibited children. This is a longitudinal study that tested the relation between children's inhibition and parents' beliefs (mothers and fathers) about the optimal parenting practices for their children from 2 to 4 years of age. An adapted version of the Behavioral Inhibition Paradigm (described above; Garcia-Coll et al., 1984) was used to measure children's behavioral inhibition. Also, The Toddler Play Observation Scale (Rubin et al., 1997) was used to assess children's behavior during the adapted inhibition paradigm. Parenting style was assessed by the Child-Rearing Practices Report Q-sort (CRPR; Block, 1981), which assesses parents' child-rearing attitudes, beliefs, and behaviors. At age 2 years, mothers' and fathers' rated their child's shyness by the social fear subscale of the Toddler Behavior Assessment Questionnaire (TBAQ; Goldsmith, 1988). And at age 4 years, child social wariness was assessed by the shyness subscale of the Colorado Child Temperament Inventory (CCTI) (Buss \& Plomin, 1984). The results of the study found that mothers' judgment of children's shyness at age 2 were negatively correlated with maternal encouragement of independence as rated on the CRPR Q-Sort. Specifically, if mothers judged their children were shy at age 2, they engaged in 
the parenting behavior that discouraged their children’s independence at age 4. Thus, this study provided evidence that parents’ perceptions of their children's inhibition influence their beliefs about optimal parenting practices. It may be that the mothers of inhibited, shy children are more likely to think that their children might be vulnerable to novel situations psychologically and physically. So, when they feel risky or unsafe in the novel environment, they will try to protect their children from being hurt by intrusive speech or behavior. Thus when taken together with the study of Rubin et al. (1997), it seems clear that parents perceptions of their children's dispositions impact the child rearing environment. Indeed, this article supported the notion that parents' beliefs about their children's shyness predict their parenting behaviors, specifically discouragement of independence. As a logical next step, Rubin and colleagues moved on to study how these childrearing environment may impact the development of inhibition.

Indeed, Rubin et al. (2002) found that maternal intrusive and controlling behavior moderated the relation between behavioral inhibition in the toddler years and social reticence in the preschool years. In this study, they tested that the relation between children's behavioral inhibition at 2 years of age and solitude and internalizing difficulties at 4 years, as well as whether parenting behaviors predicted children's social reticence at 4 years. In this longitudinal study, 108 toddlers and their mothers were participants. An adapted version of the Inhibition Paradigm (see above; Garcia-Coll et al., 1984) was used to observe and assess toddlers’ behavioral inhibition and their mothers’ parenting behavior at children's age 2. At age 4 years, 88 children were observed in the unfamiliar peer context again and mothers also rated their children's behavioral inhibition. They found that behaviorally inhibited children whose mothers displayed over-controlling, intrusive, and highly affectionate parenting behaviors at 2 
years of age displayed social reticence (or shy, wary behavior amongst unfamiliar peers) and were rated as having high levels of internalizing difficulties at 4 years of age. But, this same finding did not hold true for the 2-year-old behaviorally inhibited children whose mothers did not engage in this type of parenting (Rubin et al., 2002). Thus providing evidence that when mothers are over controlling, they undermine the development of children's social competence and independence by restraining their children from practicing and improving their social skills. In addition, maternal overprotective behavior may have lead their children think that the novel environment is unsafe to explore and then gradually become socially reticent. The results supported previous findings on the stability of behavioral inhibition from toddlerhood to preschool (Rubin et al., 1999), as well as provided evidence for the meaningful connections between children's behavioral inhibition and late social reticence moderated by maternal intrusive controlling and derision.

Further support for the detrimental role of intrusive parenting in the development of inhibited children has been found by other research groups. For instance, LaFreniere and Dumas (1992) tested the relation between parenting style and childhood anxiety and social withdrawal. They hypothesized that dysfunctional parenting style characterized by lack of predictability; intrusiveness, overcontrolling behavior; and negative affect would be related to children's anxious withdrawal. One hundred twenty-six children (66 girls, 60 boys) and their mothers were participants. Children's teachers completed the Preschool Socio-affective Profile (PSP; LaFreniere, Dumas, Dubeau, \& Capuano, 1992) to assess social competence (SC), anger-aggression (AA), and anxiety-withdrawal (AW). Based on the scores of PSP, children were placed into three categories: competent, average, or anxious-withdrawn group. Mothers and children were invited to a university lab to participate in a grocery task game in which 
mothers' parenting style and children's anxious withdrawn behavior were rated. The grocery task is a game where a miniature grocery store is laid out on a table. Fifty-six miniature items were placed on the six shelves on each side of three rows. Each child was given shopping lists and was told to "buy" each item. After the child finished shopping, he/she checked out by using a toy register. The mother of child assisted the child when needed for the first three shopping lists and child would complete other two shopping list on their own. Mother-child interaction was videotaped through the one- way mirror and coded by INTERACT coding system that is a real time microcomputer coding system developed by Dumas (1987). There were five categories of codes: actor, behavior, setting, adverb, and valence. Lafreniere and Dumas (1992) coded maternal behavior as follows:

(a) positive included laughter, helping, approving, and affectionate behavior; (b) aversive consisted of critical, punishing, disapproving, or aggressive behavior and of intrusive/coercive commands; (c) command consisted of clearly stated requests or instructions with which the person could immediately comply or refuse to comply; (d) compliance consisted of child compliance within $10 \mathrm{~s}$ with a preceding maternal command; (e) noncompliance consisted of the child's active refusal to comply within $10 \mathrm{~s}$ with a preceding maternal command; (f) positive affect consisted of the expression of positive emotions (e.g., smiling) that accompanied any coded behavior; and (g) negative affect consisted of the expression of negative emotions (e.g., loud or sarcastic tone of voice) (Lafreniere \& Dumas, 1992, p. 392).

The results indicated that mothers of the anxious withdrawn children were significantly more controlling of their children than mothers of $S C$ and $A V$ children; further, mothers of anxious, withdrawn children expressed more negative affect toward their children than the 
mothers of the other two groups. This study again well supported that dysfunctional parenting practice, such as critical, punishing, disapproving, or aggressive behavior and intrusive/coercive commands are significantly associated with children's socially withdrawal. In addition, one of characteristics of dysfunctional parenting that was not reported by Rubin and colleagues (1997, 1999, 2002) was maternal negative affect, and was found to be a predictor for the children's social withdrawal. The reason might be that in order to avoid their mothers' sarcastic comments, the children became unwilling to explore in the novel setting and gradually become social withdrawal. Therefore, the study findings are consistent with the study of Rubin et al. (1997): The more mothers controlled their children's behavior, the more children behaved in a socially withdrawn fashion. In conclusion, above a series of empirical studies well supported that dysfunctional parenting (e.g., oversolicitous, overprotective, intrusive, and negative affect parenting) is significantly associated the development of child inhibited, shy behavior.

Thus, it appears that parenting marked by intrusive, controlling behavior and inappropriate affect (either highly warm or highly negative) is associated concurrently and longitudinally with behavioral inhibition. Interestingly, there have been studies that report that intrusive parenting may reduce behavioral inhibition. For instance, Park, Belsky, Putnam, and Crnic (1997) reported contradictory findings to those reported by Rubin and colleagues (e.g., Rubin et al., 1997; Rubin et al., 2002). In this study, 125 firstborn boys and their fathers and mothers participated. Children's temperament was assessed at 12-13 months and parenting style of mothers and fathers with the most and least inhibited children was assessed at 15, 21, 27, and 33 months. At 12 and 13 months, infants were videotaped in a university laboratory to assess their positive and negative emotionality. This session included the standard Strange Situation (Ainsworth, Blehar, Walters, \& Wall, 1978), and a four-episode frustration task (Stifter 
\& Grant, 1993) where the following tasks were completed: “(a) parents played with child with a toy, then (b) withdrew the toy and refrained from interacting with the child, then (c) returned the toy to the child but continued to ignore the child, and finally (d) reengaged the child in play" (Park et al., 1997, p. 220). Also, at 15, 21, 27, and 33 months, researchers observed parenting via visiting in the home. Parents were instructed to act as they usually do at home, and the following characteristics were coded: positive affect (e.g., hugs, kisses, smiles, and positively rewarding verbal comments), negative affect (e.g., anger and hostility), sensitive parenting (parents adjust their behavior in order to satisfy their child's goal and needs), intrusive parenting (parents place their own goals and agendas on the child without considering child's feeling), and detached parenting (parents seem uninvolved or unresponsive to their child). Children’s inhibition was assessed with identical inventories as at 12-13 moths in the university lab with mother at 36 months and with the father at 37 months.

Park et al. (1997) reported that highly sensitive, low intrusive parenting was associated with the highest levels of children's inhibition at 37 months. This finding is surprising since other studies have reported that highly intrusive parenting is associated with higher levels of inhibition (e.g., Rubin et al., 2002). It is important to note that the testing conditions differed in that their sample was comprised entirely of boys and observations of parenting happened in the home environment in addition to the laboratory. However, it may be that parental intrusive behavior signals to children that they should interact with peers. Thus, further research is required to clarify the seemingly contradictory findings between Park et al. (1997) and Rubin et al. (1997; 1999) as well as LaFreniere and Dumas (1992). Nonetheless, it is clear that parenting can ameliorate or exacerbate the stability of behavioral inhibition.

In conclusion, in early childhood, if parents feel that their children are fearful or shy, they 
may believe that they must protect their children from being hurt, and behave in an intrusive, overprotective fashion. However, such beliefs may do harm because parental protection may discourage children's independent attempts to explore the unfamiliar situations, and thus hinder their socio-emotional development. Indeed, these relations are well-established (e.g., Lafreniere \& Dumas, 1992; Park et al., 1997; Rubin et al., 1997; Rubin et al., 2002), but it is less established how other aspects of the parent-child domain may further impact these relations. One factor that has received scant attention is parenting stress.

\section{Parenting Stress and Dysfunctional Parenting}

From the review above, it seems that parenting does affect, is associated with, and can exacerbate children’s behavioral inhibition (e.g., Park et al., 1997; Rubin et al., 2002).

Although, there have been many studies about how poor parenting influences the development of behavioral inhibition (e.g., Rubin et al., 2002), there are many variables that may lead to poor parenting practices, and one important contributor is parenting stress (e.g., Abidin, 1992; Assel et al., 2002; Chan, 1994; Crnic \& Low, 2002; Deater-Deckard, 1996; Deater-Deckard, 1998; Erath et al., 2009; Gelfand et al., 1992; Guajardo et al, 2009; Holden \& Banez, 1996; Mills \& Rubin, 1990). Specifically, parenting stress may lead to poor parenting which, in turn, may negatively influence child development (Abidin, 1990; Deater-Deckard, 1996; Guajardo et al., 2009). Indeed there have been several studies that concluded that parenting stress affects parenting behavior, child development, as well as externalizing and internalizing behavior (Conger et al., 1992; Conger, et al., 1995; Feldman et al., 2004; Guajardo et al., 2009; Mills \& Rubin; 1990; Webster-Stratton \& Hammond, 1988). However, very few researchers have examined the relation among parenting stress, parenting practices and the development of children's behavior inhibition (for an exception, please see Mills \& Rubin, 1990). 


\section{The Definition of Parenting Stress}

Parenting stress has been defined as the difficulty that arises from the demands of being a parent (Abidin, 1995; Ostberg \& Hagekull, 2000). Parenting stress occurs when the resources (e.g., economic resources; social support; spousal support) cannot meet the demands of parenthood (Deater-Deckard, 1996). Parents often feel more stressed when they have less support from partners, family members, and friends (Belsky, 1984; Bonds \& Gondoli, 2002; Chan, 1994), when they perceive themselves to be incompetent parents (Mash \& Johnston, 1990), or when they lack economic resources (Deater-Deakard, 1996; Mills \& Rubin, 1990). It is common for parents to feel stressed when their children ask them to satisfy demands, such as feeding, comfort, and attention (Abidin, 1995; Deater-Deckard, 1998). Although children become more autonomous as they grow, they still continuously place demands on their parents (Deater-Deckard, 1998). Generally, normal parenting responsibilities lead to higher levels of stress (Koeske \& Koeske, 1990), particularly during the preschool period (Kuczynski \& Kochanska, 1990). In a study by Crnic and Hoffman (2005), they found that parenting stress, including life stress and daily hassles, were stable over the preschool period. In turn, such cumulative stress may elevate the risk for dysfunctional parenting and child behavior problems. Especially, if parents feel their children are moody, demanding, and difficult, they tend to report high levels of parenting stress (Ostberg \& Hagekull, 2000).

In 1976, Abidin and Burke developed a model of the relation between parenting stress and parenting, which aided in the design of the Parenting Stress Index (PSI) (See Figure 1). In this model, the factors that contribute to parenting stress and subsequent dysfunctional parenting are clearly outlined. Specifically, the model emphasizes multi-factorial parenting stressors, for example stress can originate in the parental domain in which factors include parental depression, 
self-efficacy, role restrictions, relationship with spouse, social support, health and parental attachment (Abidin, 1976). Stress can also originate from the child domain such as children's poor adaptability (inability to handle change) and acceptability, difficult temperament, demandingness, mood, and hyperactivity (Abidin, 1976). Finally, stresses can come from life stress domain such as loss of employment or death of a close relative (Abidin, 1976)

\section{Parenting Stress Index (PSI)}

Parenting stress is often assessed via Abidin's (1976) Parenting Stress Index; thus a review on the development of the PSI seems warranted. The PSI is an instrument that is used to measure parenting stress and dysfunctional parenting around child, parent, and situational characteristics. The PSI includes three domains: Child Characteristics Domain, Parent Characteristics Domain, and an optional Stressful Life Events Domain.

It is well known that in order to acknowledge the validity of any instrument, the instrument should be used in broad studies and in diverse population. The PSI was used in over 250 studies to respectively discriminate parenting distress as well as predict dysfunctional parenting behavior and poor child development and behavior problems in a wide range of populations. In addition, the PSI was used in over 50 studies as a program evaluation instrument that showed sensitivity to the change of parenting stress. So, PSI is a very reliable measurement of parenting stress.

\section{Parenting Stress, Poor Parenting and Child Development}

Deater-Deckard (1998) laid out three hypotheses about the relations between parenting stress, parenting practices, and child development. Specifically, he proposed: (a) Parenting stress causes poor parenting; (b) Poor parenting causes maladjustment in children; and (c) Parenting behavior mediates the link between stress and child adjustment. Given the aim of the proposed 
study, I reviewed related papers around the Deater-Deckard's the first hypothesis and the third hypothesis.

Hypothesis 1: Parenting stress causes poor parenting. Parents who report high levels of stress have been found to be less responsive (Gelfand et al., 1992), more authoritarian (Deater-Deckard, 1996), more punitive (Guajardo et al, 2009), more power assertive (Mills \& Rubin, 1990), neglectful (Assel et al., 2002), harsh (Erath et al., 2009), and, in extreme cases, abusive (Chan, 1994; Holden \& Banez, 1996) in interactions with their children. Moreover, mothers who report more memories of harsh and neglectful parenting were more likely to report higher levels of emotional stress (Assel et al., 2002). There have been numerous reviews indicating a link between parenting stress and parenting practices (e.g., Crnic \& Low, 2002; Deater-Deckard, 1998). Abidin (1992) constructed a model on “determinants of parenting behavior” to predict parenting behavior. This model included components of Patterson's Behavioral Model, Abidin’s initial Model of Parenting Stress, and Belsky’s Process Model of Determinants of Parenting to form a comprehensive model detailing the relation between parenting stress and parenting behavior (see Figure 2).

In this model, several stressors contribute to parenting stress, which leads to certain parenting behavior moderated by some variables, such as social support, parenting alliance, parenting skills, material resources and cognitive coping that increase or decrease parenting stress. For example, if parents feel incompetent in parenthood, they may become stressed; or if parents only can access to limited resources, they also feel stressed. Of course, if incompetent parents were provided with strong social support, such as obtaining parental training to improve their coping skills, it will likely decrease their stress.

This model is supported by several empirical investigations. For instance Gelfand, Teti 
and Fox (1992) found that highly stressed parents (stress caused by depression) may lose their ability to care for their children in a warm, sensitive, and competent manner. They hypothesized that stressed parents are less affectionate with their infants because parenting stress affects a caregiver's ability to assess infant cues and to provide appropriate care and comfort. In this study, 124 families with infants (including 71 clinically depressed mothers and 53 non-depressed mothers) were assessed. Home visits were conducted where data from questionnaires and observations of mother-infant interaction were collected. During a second home visit, blind observers assessed the mother's behavior with her baby during a 30-40 minute time period using a scale developed by Lyons-Ruth, Zoll, Connell, and Grunebaum (1986) based on Ainsworth's concept of good mothering (Ainsworth, Blehar, Waters, \& Wall, 1978). The 5-point rating scales measured "maternal sensitivity (alertness and responsivity to infant signals), warmth (demonstrated affection toward the infants), affective responsivity (animation), disengagement (disconnectedness from infant physically or socially), and anger (any expression of hostility) in both feeding and free-play context” (Gelfand et al., 1992, p. 264). The Parenting Stress Index (PSI; Abidin, 1986) was used to measure parenting stress (see description above). Researchers found that the depressed mothers reported higher levels of parenting stress and received less social support than non-depressed mothers. In addition, stressed mothers engaged in less optimal parenting behavior, such as lower scores of sensitivity, warmth, animation, and engagement with the infant, and more expressions of anger, all indices of dysfunctional parenting. Thus, it seems that stress may interfere with mothers’ parenting competence. For example, stressed mothers might be more likely to lose their temper when interacting with their children. In addition, stressed mothers are possibly incompetent in reading their children's needs which hinders the mothers' ability to provide their children with support. Thus, the findings from this 
study provide evidence that parenting stress negatively influences parent-child interactions.

In another study, Deater-Deckard and Scarr (1996) investigated the moderating role of marital satisfaction on the relation between parenting stress and parenting practices and the development of subsequent child behavior. Of particular interest to the proposed study were their findings about the relation between parenting stress, authoritarian discipline, and child misbehavior. In this study, families with toddlers were the participants (mean age of children was 30.82 months). The Parenting Stress Index-Short Form (PSI/SF; Abidin, 1990) was used to measure parenting stress and dysfunctional parenting. The emotional subscale of the EAS Temperament Scale (Buss \& Plomin, 1984) was used to measure children’s emotional liability including subscales of sociability, shyness, and activity. This scale involves questions regarding how easily the child becomes distressed and how difficult the child is to soothe. The Manageability Index was used to measure child's misbehavior, such as hyperactive and difficult behavior. Deater-Deckard and Scarr (1996) observed that parents who reported higher levels of parenting stress were more likely to be authoritarian, harsh, and negative in their parenting which increased children's misbehavior. The results reported that the correlation between parenting stress, authoritarian discipline, and child misbehavior was significant and moderated by the marital satisfaction and children's age, with unhappy parents and parents of older children indicting feelings of greater stress. It may be that stressed parents are more likely to engage in the authoritarian discipline than non-stressed parents because the stress impacts their levels of patience with children. So, when children's misbehavior arises, the stressed parents might hope to stop it quickly, and authoritarian discipline possibly is an effective way to meet the parents' needs. Furthermore, the moderator roles of marital satisfaction are that on the one hand, if parents had a happy marriage life, for instance, getting more support from their partners, parental 
stress level decreased. Moreover, children's age moderates the relation as when children grow up, parents may feel that as their children seek greater independence, that their parents might think children’s behavior becomes problematic, and may engage in more authoritarian discipline. Finally, it is important to note that the association between parenting stress, power assertive discipline, and child behavior were small but reliable (regression coefficients ranged from 0.13 0.26). Thus, the findings of the study also lend some support for the relations between parenting stress and dysfunctional parenting. Comparing to Gelfand and colleagues (1992), this study extended the understanding of how poor parenting that results from stress impacts children's emotional development.

In another study, Chan (1994) tested the association between parenting stress and child abuse. Thirty-seven abusive mothers were compared with of non-abusive mothers. Both abusive and non-abusive mothers had similar demographic and socioeconomic background but were recruited in different settings, for instance, abusive mother were recruited from the Child Protective Services Unit of the Social Welfare Department, Hong Kong and non-abusive mothers were from nurseries and child care centers in different areas of Hong Kong. The Parenting Stress Index (PSI; Abidin, 1983) was used to measure parenting stress and the Maternal Social Support Index (MSSI; Pascoe, 1981) was used to assess social support of mothers. Results indicated that abusive mothers had higher levels of stress and had less social support than non-abusive mothers. That might be because high levels of stress (e.g., lower socioeconomic status, insufficient social support) increased the maternal risks of child abuse that is an example of extremely dysfunctional parenting. Thereby it also lends evidence that parenting stress is related to disruptions in parenting process.

In sum, researchers have tested and provided evidence that parenting stress is associated 
with dysfunctional parenting. Specifically, stressed parents are more likely to engage in following non-optimal parenting style, such as non-responsive (Gelfand et al., 1992), neglectful (Assel et al., 2002), overreactive (Guajardo et al., 2009), harsh (Erath et al., 2009), high power assertive (Mills and Rubin, 1990) authoritarian (Deater-Deckard, 1996), or even abusive parenting (Chan, 1994; Holden \& Banez, 1996). Although, the above noted studies did not directly examine whether the association between parenting stress and overprotective parenting, they provide support for the notion that parenting can negative impact the parenting process.

\section{Hypothesis 3: Parenting practices mediate the link between stress and child}

adjustment. As noted above Deater-Deckard (1998) also proposed that parenting behavior mediates the link between parenting stress and child adjustment. This is notion that mirrors Belsky’s (1984) model of the determinants of parenting. Specifically, Belsky (1984) proposed that contextual stress, such as marital relations, work, and social network, are major determinants of parenting that can both directly and indirectly influence children's development. Belsky constructed the Process Model of the Determinants of Parenting to indicate a pathway between parenting contextual stress which influences parenting practices that further influence child development (see Figure 3).

In support of Belsky's model and Deater-Deckerd's (1998) hypothesis, several studies have empirically shown that stress interferes with parenting practices that aid in adaptive child development. For instance, Feldman, Eidelman, and Rotenberg (2004) tested the associations between parenting stress, non-sensitive parenting, and child cognitive competence in sets of multiples and singleton children. Specifically, 23 sets of triplets, 23 set of twins and 23 singletons were included in the study. The researchers observed interactions between mothers and children at birth, 3, 6 and 12 months to assess maternal sensitivity. They also assessed 
children's cognitive development via the Bayley Scales at 12 months, and coded children's symbolic play during the 12 month by assessment during mother-child interaction. Further, mothers completed the Parenting Stress Index/Short Form (PSI/SF; Abidin, 1990) to obtain a global index of parenting stress. Using structural equation modeling, Feldman and colleagues (2004) found that parenting stress was negatively related to maternal sensitivity, which negatively influenced infants' cognitive development and symbolic play. Thus, it is clear that parenting stress not only impacts the caregiving relationship, but also indirectly influences children's cognitive and social growth.

In another study, Guajardo, Snyder and Petersen (2009) tested the relation between parenting stress, dysfunctional parenting and child internalizing and externalizing behavior. In this study, 47 four-year-olds and their parents participated. The Parenting Scale (PS; Arnold et al., 1993) was used to examine parenting style, especially assessed parenting responses to child misbehavior; two subscales were used to measure overreactive parenting (harsh verbal commands and physical punishment) and lax parenting (submitting or giving in to children's demands). Parenting stress and the quality of parent-child interactions were measured by the Parenting Stress Index (PSI; Abidin, 1995). Parents and their children were also observed during a free-play and clean-up session, where parenting responsiveness (imitations, praise) and intrusiveness (criticism, commands) were coded. Finally, children’s behavioral problems (internalizing/externalizing behaviors) were assessed via parental report using the Child Behavior Check List (CBCL; Achenbach, 1991). The results well supported the hypothesis that parenting stress was associated with parental laxness and overreactivity, parenting stress also predicted child internalizing and externalizing behavior and parental laxness and overreactivity was correlated with child internalzing and externalizing behavior. That means that parenting 
stress directly and indirectly influences children’s behavioral problems. The results indicated that parenting stress significantly predicted overreactive parenting, lax parenting, and child behavior problems.

Although this study investigated other types of dysfunctional parenting, such as overreactive and lax parenting that was different from non-sensitive parenting examined by Feldman and colleagues (2004), such dysfunctional parenting is also associated with the children's internalizing and externalizing behavior. Thus, it appears the results of this study supported that parenting stress is related to dysfunctional parenting which further negatively influences children's behavior problems.

The mediating mechanism from parenting stress, parenting practices and children's adjustment was also investigated in a study by Conger, Patterson and Ge (1995). This study tested a mediating model in which acute stress that is defined as undesirable life events experienced by parents may relate to child adjustment via maternal depression and maternal discipline practices. They hypothesized that highly stressed mothers are more likely to be depressed, which would affect parenting practices that may influence children's adjustment. The participants were from two datasets: The Oregon Youth Study (OYS) and the Iowa Youth and Families Project (IYFP). In the OYS sample, participants were 75 intact families (with biological parents) and their elementary school children; in the IYFP study, the participants were 451 seventh graders and their biological parents. In OYS sample, they measured the acute stress by variables in three dimensions: “(a) sharp decrease in income, (b) other family member serious medical problem, and (c) frequency of times the respondent experienced injury or illness requiring medical attention” (Conger et al., 1995, p.83). While in the IYFP study, stress was measured via PERI measure of objective life-event (Dohrenwend, Krasnoff, Askenasy, \& 
Dohrenwend, 1978) where parents were asked whether any of 35 different negative events (e.g., job disruptions, financial problems, illness or injury) ever happened to them during the past 12 months.

Parental depression was measured via the CES-D (Radloff, 1977) and Lubin Checklist (Lubin, 1963) in the OYS sample; while in the IYFP, parent depression was rated by self-report via the SCL-90-R (Derogatis, 1983), by spouse report based on the scores for spouse-reported depression, and by observer report based on the scores for observer-reported depression. In the OYS sample, parent discipline was assessed via observation and interview; similarly, in the IYFP sample, parental discipline was assessed by report from parent, spouse, and observer. Finally, in the OYS and IYFP samples, adolescent deviance was comprised of ratings of antisocial behavior, academic achievement, and peer relationship.

The results were obtained in two steps. In the first step, they found that the acute stress reported by mothers was positively related to maternal depression. In the second step, they found that association between maternal depression and children’s deviancy, such as low academic skills, poor relations, and especially high antisocial behavior. The reason might be that stressful life events or condition resulted in parental depressed mood and depressed parents less effectively supervised their children’s behavior. Under insufficient parental supervision, children are likely to be involved in deviant behavior. In addition, depressed parents possibly demonstrated high levels of irritability and a tendency to be easily upset and angry during the interaction with their children. In terms of social learning mechanisms, children of depressed parents may have poor competence of emotion adjustment or they may think behaving aggressively is a good way to solve interpersonal conflict. Further, these children may be rejected by their peers and then have poor peer relations. So, this study further examined and 
confirmed a mediating pathway that is acute stress was positively related to disrupted discipline practices that further negatively influenced children’s adjustment.

Conger and colleagues (1992) also examined the influences of chronic stress, such as economic pressure and marital conflict that influence the adolescent adjustment. In this study, the 205 seventh-graders and their families participated in the study, and two home visits were conducted. In the first home visit, each family member filled out a set of questionnaires that described characteristics of the family and the family economic circumstances. Two weeks later, a second home visit was conducted. During this visit, family recollections of disagreements were videotaped and interactions between family members were coded. Parents also completed an assessment of economic hardship and depression. Nurturant/involved parenting was assessed by a 5-point Likert scale that includes parental warmth, involvement, psychological closeness, age-appropriate expectations, monitoring, and positive indicator of internalization (Conger et al., 1992, p. 531). Also, the seventh grade children completed an assessment of their adjustment, which included items regarding school performance, positive peer relations and self-confidence. The results of study indicated that family economic pressure was positively correlated with father's and mother's depression that was positively associated with marital conflict. And then marital conflict further negatively influenced mother’s nurturant/involved parenting that was detrimental to adolescents’ positive adjustment. The reasons might be that when parents were faced to family economic pressure, they became frustrated or angry. Under such bad emotion, the conflicts of between husband and wife were inevitable and the conflicts further destroyed the nurturant/involved parenting practice. Without nurturant/involved parenting, adolescent would be less support or monitored by their parents. In addition, the parenting practices become harsh because of parental angry emotion. Finally, 
adolescents became antisocial that is consistent with the findings of Conger's study in 1995.

Conger and colleagues’ (1992, 1995) studies well support Deater-Deckard’s third hypothesis: Parenting practices mediate the relation between parenting stress and child adjustment. This hypothesis was also supported by the work of Webster-Stratton and Hammond (1988). In this study, they investigated the relation between maternal depression, life stress, parenting, and child adjustment. Ninety-five families and their children with conduct problems were recruited: Approximately half of the samples were families where the mother was depressed. In this study, mothers were interviewed or completed questionnaires regarding their child's negative behaviors, level of depression, and parenting stress. A home visit was conducted to observe parent-child interactions and five mother behaviors (praise, commands, criticism, physical negative behaviors, and total interaction) and two child behaviors (deviance, noncompliance) were recorded. In addition, teachers completed questionnaires to rate children's adjustment in the classroom.

They found that depressed mothers had higher levels of stress than non-depressed mothers and also reported more negative life events. Moreover, depressed mothers reported their children had more externalizing and internalizing behavior, and they were observed to engage in more derisive, critical parenting practices. However, when teacher-reported internalizing and externalizing problems were used as the dependent measure, the opposite was found: the children of depressed mothers had fewer behavior problems than the children of nondepressed mothers. Moreover, in the home observations there were no behavior differences were observed between children with depressed mothers and children with non-depressed mothers. There might be following reasons for the outcomes reported above. First, maternal depression likely increased mothers’ negative judgment to their children’s behavior problems. 
Second, the most family observations happened during the family dinner and children may have less opportunity to engage in deviant behavior. Regardless, it is clear that depressed mothers appear to have higher stress levels than non-depressed mothers; further, increased stress appears to be linked to less optimal parenting practices (e.g., criticism). In turn, such critical statement influenced their child adjustment and internalizing/externalizing behavior reported by parents in this study.

In sum, although researchers employed different measurements and methods, it seems clear that parenting is a mediator between parenting stress and children's adjustment. Specifically, it appears that highly stressed parents may engage in non-optimal parenting practices (e.g., insensitive, neglecting, overcontrolling, overreactive, laxing, or even abusive parenting) which further influence the development of children's adjustment. However, after a review of the relevant literature, it seems that no studies to date have examined these relations in an investigation of children's inhibited/shy behavior. One relevant study has been conducted, however, this study only examined the relation between parenting stress and parents' beliefs about children’s inhibited, shy behavior. Specifically, Mills and Rubin (1990) investigated these processes in a sample of 122 mothers (52 girls, 70 boys) and 67 fathers (26 girls, 41 boys) of 4-year-olds were participants. They measured the parental beliefs toward child's aggressive and withdrawal behavior by presenting parents four stories in which aggressive behavior and withdrawn behavior were depicted. After being presented with the stories, parents were asked to rate how they felt seeing their own child act this way. For example, they were asked the question, "How do you feel when you see your child act this way several times in a row" (Mills \& Rubin, 1990, p. 141)?

Parents’ responses were coded for attributions and socialization strategies. Specifically, 
attribution was classed into "internal stable factors, internal unstable factors, and external factors. Internal stable factors refer to trait or dispositions consistent across situations and over time; internal unstable factors refer to temporary or changeable conditions, such as age or age-related factors; and external factors refer to situational influences” (Mills \& Rubin, 1990, p.141-142). The three types of socialization strategies were coded in the study, such as high in power assertion (e.g., punishment, strong commands), moderate in power assertion (e.g., reasoning, modeling, and gentle directions) and low in power assertion (e.g., asking the child for information or redirecting the child).

In addition, they also measured the parents' stress by measuring Life Circumstances (e.g., parental occupational status, level of education, and estimated socioeconomic status of the family) and Perceived Social Support measured by Personal Resource Questionnaire (PRQ, Brandt \& Weinert, 1981). PRQ is a seven-point Likert scale which includes 25 statements about supportive or self-enhancing social contacts.

Mills and Rubin (1990) found that trait attribution was positively correlated with mother's choice of "no response" toward their child's withdrawal behavior; meaning that the more mothers attributed withdrawal behavior to a child's disposition, the less they might make effort to change it. Specifically, if mothers of inhibited children ascribed their children's behavior as a nature problem (e.g., their children born with inhibited/shy trait.), they possibly think it is useless to try to moderate it. Also, they found that mothers under unfavorable circumstances (e.g., low in occupational status or low levels of social support), trait attribution tended to predict nonresponsive parenting. Finally, they found mothers with low occupational status were more likely to use high-power assertive socialization strategies toward their child's withdrawal behavior. So, this study indicates that stress may influence parenting practices (e.g., 
high power assertive parenting). However, it is regretful that the study did not examine whether non-responsive parenting or high power assertive parenting is a mediator of between parenting stress and the development of children's inhibited/shy behavior. Thus, it seems timely to investigate how parenting stress and parenting practices may impact the development of inhibited, shy behavior.

In conclusion, although the studies reviewed above did not directly investigate whether specific parenting practices, such as overprotective, authoritarian, or authoritative parenting, mediate the relation between parenting stress and the development of inhibited, shy behavior in childhood, they do lend support on that parents with high levels of parenting stress are more likely to engage in dysfunctional parenting practices that in turn influences children's adjustment. Therefore, above literature review generally supports the following (a) parents with high levels of parenting stress are more likely to engage in dysfunctional parenting practices; (b) dysfunctional parenting practices negatively influences children's adjustment; and (c) parenting practices act as mediators between parenting stress and child internalizing/externalizing behavior. In conclusion, based on these general findings, I sought to investigate whether parenting stress would influence parenting practices that would impact inhibited, shy behavior in preschool-aged children.

\section{Hypotheses}

In the proposed study, I tested a theoretical mediation model (see Figure 4) similar to that suggested by Abidin (1990) and Belsky (1984), parenting practices were examined as mediators of the relation between parenting stress and inhibited, shy behavior. In this model, it was expected that parenting stress would influence parenting practices which would, in turn, impact children's inhibited, shy behavior. Based on the theoretical model, I tested three mediation 
models in which Authoritative, Authoritarian, and Overprotective parenting practices are assessed as mediators in the relation of parenting stress and children's inhibited, shy behavior.

Hypothesis 1: It was expected that parents who report low levels of stress would endorse high levels of functional parenting practices, such as authoritative parenting, which would predict low levels of child inhibited, shy behavior.

Hypothesis 2: It was expected that parents who reported high levels of stress would engage in high levels of dysfunctional parenting practices (either authoritarian or overprotective parenting) which would predict high levels of child inhibited, shy behavior. 


\section{CHAPTER 3}

\section{METHOD}

\section{Participants}

Twent y-seven mothers (mean age $=34$ ) and their children (14 boys, 13 girls; mean age 3.5 years) participated in the study. The majority of the children (85\%) were White (7\% black, 7\% Bi-racial); the majority (92\%) of the mothers were also White (4\% Black, 4\% Bi-racial). Eighty-two percent of the mothers reported being married to the target child's biological father, and all but one of the mothers had completed at least a University degree. The annual household income for $70 \%$ of the sample was above $\$ 75,000$ per year.

\section{Design}

The current study was quantitative in design, and involved data collection via four questionnaires. In this study, the independent variable was Parenting Stress, the dependent variable was the scores of child inhibited, shy behavior, and the mediating variables are three types of parenting practices, such as Authoritative Parenting, Authoritarian Parenting, and Overprotective Parenting.

\section{Recruitment of the Sample}

Participants were drawn from preschools and daycare centers in Morgantown, West Virginia. In addition, participants were recruited via advertisements posted in the hallways of West Virginia University buildings, the local cable television station, and at local businesses.

\section{Procedure}

After agreeing to participate, participants were contacted and asked to complete a packet of seven questionnaires (either via secure website or paper) and a laboratory visit; separate questionnaire packets were distributed to mothers and fathers. Of relevance to the proposed study 
are the following questionnaires: Demographics; Parenting Stress Index/Short Form; Parenting Practices Questionnaire, and the Child Behavior Questionnaire-Short Form. Again, all measures were completed by mother and father; however, the only maternal data were used herein. The measures are described in detail below.

\section{Instrumentation}

Demographics Information Questionnaire. The Demographics Information Questionnaire (Appendix A) was used to collect descriptive data about the parents and child. Child data included child age, the relationship between parents and child (e.g. biological, adopted or foster), and child race (e.g. American Indian, Alaska Native, Asian, Black or African American, Native Hawaiian or Other Pacific Islander, White or Caucasian, Bi- or Multi-racial: please specify, Other: please specify). In addition, mothers completed questions about mother's and father's race (e.g., American Indian, Alaska Native, Asian, Black or African American, Native Hawaiian or Other Pacific Islander, White or Caucasian, Bi- or Multi-racial), marital status (e.g., Married, Separated, Divorced, Common law, Single, Living with partner), occupation, education level and income.

Parenting Stress Index/Short Form (PSI/SF). Parenting Stress Index/Short Form (PSI/SF; Abidin, 1995; Appendix B) was developed from the full-length Parenting Stress Index by Abidin (1976). It is used to measure parenting stress that is from the area of parental distress, dysfunctional parenting and difficult child. Accordingly, three subscales are included in PSI/SF: Parenting Distress (PD), Parent-Child Dysfunctional Interaction (P-CDI), and Difficult Child (DC). PD assesses the distress experienced by a parent related to parenting; $P-C D I$ assesses parental perception that their child does not satisfy parent's expectation and the roles of parent are not reinforced by the interaction with child; and $D C$ assesses child behavioral 
characteristics that is difficult to be managed. There are total 36 items in PSI/SF and 12 items are in each subscale. The form of responding includes SA (strongly agree), A (agree), NS (not sure), D (disagree), or SD (strongly disagree). The tested items of PSI /SF directly come from $P S I$, thus all tested items in PSI /SF are included in PSI with identical wording. Abidin et al. (1995) also tested test-retest reliability over a 6-month period and reported the following reliability coefficients: $\quad P D$ was .85; $P$ - $C D I$ was .68; and $D C$ was .78.

In the present study, only the total stress score was used (an aggregate of the above-noted subscales). The Cronbach's Alpha for the PSI/SF Total was .74.

The Adapted Parenting Practices Questionnaire. The Adapted Parenting Practices Questionnaire (Appendix C) was used to measure maternal self-reported parenting style, and the current study focused on the subscales of authoritative and authoritarian parenting (Robinson, Mandleco, Olsen \& Hart, 1995). Twent y-seven items comprised the Authoritative parenting scale $(\alpha=.86)$; including items from the following subscales: (a) Warmth and Involvement with 11items; (b) Reasoning/Induction with 7 items; (c) Democratic Participation with 5 items; and (d) Good Natured/Easy Going with 4 items (Robinson et al., 1995, p.827). Authoritarian parenting $(\alpha=.75)$ was computed from a total of 19 items (one item from the non-reasoning, punitive scale was dropped, specifically, "I appear to be more concerned with my own feelings than with my child’s feelings.”) included the following subscales: (a) Verbal Hostility with 4 items; (b) Corporal Punishment with 6 items; (c) Nonreasoning, Punitive strategies with 6 items; and (d) Directiveness with 4 items (Robinson et al., 1995, p.827).

Nelson, Hart, Olsen, and Robinson (2000) adapted the PPQ by adding 10 questions to tap into overprotective parenting. Examples include, "get anxious when child tried to do something new or difficult and "readily intervenes if there is a chance child will fail at something." The 
overprotective scale has been used in other studies beyond Nelson and colleagues (2000) (e.g., Coplan, Prakash, O’Neil, \& Armer, 2004), and Cronbach’s alpha was .70 for the current sample.

Child Behavior Questionnaire-Short Form. Mothers also completed the Child Behavior Questionnaire - Short Form (Putnam \& Rothbart, 2006; Appendix D) which was used as a measure of inhibited, shy behavior. The CBQ-SF is an adapted version of the standard form of the CBQ (Rothbart, Ahadi, \& Hershey, 1994; Rothbart, Ahadi, Hershey, \& Fisher, 2001). The Short Form of the CBQ contains 94 items, and items are rated on a seven-point Likert scale which range from 1 (extremely untrue of your child) to 7 (extremely true of your child). In addition, participants could choose NA (not applicable).

In the proposed study, the focus was on the items and scales that assess shyness and fear. The items from the shyness and fear scales were aggregated to yield an index of inhibited, shy behavior $(\alpha=.78)$.

\section{Analytic Strategy}

Following Baron and Kenny (1986), four separate regression analyses were conducted to test parenting practices as a mediator of the relation between parenting stress and children's inhibited, shy behavior. In the first analysis, scores of inhibited, shy behavior were regressed on parenting stress. In the second analysis, parenting practices were regressed on parenting stress. In the third analysis, the scores of inhibited, shy behavior were regressed on parenting practices. Finally, the scores of inhibited, shy behavior were regressed on parenting stress while controlling for parenting practices. The theoretical mediation model is depicted in Figure 4.

According to Baron and Kenny (1986), a mediating effect is found if a significant relation is found between Parenting Stress and Parenting Practices (path a), if a significant relation is found between Parenting Practices and Inhibited, Shy Behavior (path b) and if the link between 
Parenting Stress and Inhibited, Shy Behavior (path c) is insignificant after controlling the effect of Parenting Practices. Specifically, in the Tested Model 1 (see Figure 5), it was hypothesized that Parenting Stress would be negatively correlated with Authoritative Parenting (path a); and Authoritative Parenting would be negatively correlated with Inhibited, Shy Behavior (path b) and Parenting Stress would be positively correlated with Inhibited, Shy Behavior (path c). However, it was expected that the relation between Parenting Stress and Inhibited, Shy Behavior would be mediated by Authoritative Parenting.

In the Tested Model 2 (see Figure 6), it was hypothesized that Parenting Stress would be positively correlated with Authoritarian Parenting (path a), Authoritarian Parenting would positively correlated with Inhibited, Shy Behavior (path b) and Parenting Stress would be positively correlated with Inhibited, Shy Behavior (path c). However, it was expected that the relation between Parenting Stress and Inhibited, Shy Behavior would be mediated by Authoritarian Parenting.

In the Tested Model 3 (see Figure 7), it was hypothesized that Parenting Stress would be positively correlated with Overprotective Parenting (path a), Overprotective Parenting would be positively correlated with Inhibited, Shy Behavior (path b) and Parenting Stress would be positively correlated with Inhibited, Shy Behavior (path c). However, it was expected that the relation between Parenting Stress and Inhibited, Shy Behavior would be mediated by Overprotective Parenting. 


\section{CHAPTER 4}

\section{RESULTS}

The means and standard deviations for all variables of interest were presented in Table 1. The correlations between all variables were presented in Table 2. Total stress was significantly, negatively correlated with authoritative parenting. That means that parents with high levels of stress engaged in low levels of authoritative parenting. In addition, authoritarian parenting was significantly, negatively correlated with authoritative parenting, indicating that parents who engaged in high levels of authoritative parenting engaged in low levels of authoritarian parenting. It is worth mentioning that the authoritarian parenting was significantly negatively correlated with children's inhibited/shy behavior.

Authoritative parenting was significantly negatively correlated with parenting stress, which is consistent with the expectation that parents with low levels of parenting stress will engage in high levels of authoritative parenting. Furthermore, authoritative parenting was significantly positively correlated with inhibited, shy behavior. Finally, overprotective parenting was positively correlated with children's inhibited/shy behavior; thus indicating that parents who engage in high levels of overprotective parenting have children who are reported to display high levels of inhibited, shy behavior.

\section{Mediation Models}

The data were then analyzed to test the hypotheses regarding parenting practices (authoritarian, authoritative, and overprotective) as a mediator between parenting stress and inhibited, shy behavior. Specifically, three models were tested (see Figures 5 - 7). 
In all models, mediation cannot be assumed, as parenting stress was not predictive of inhibited, shy behavior $\left(\Delta R^{2}=.03 ; F\right.$ Change $\left.=0.66 ; n s ; \beta=-.16\right)$. However, when the models were tested, it seems that parenting stress has an indirect association with inhibited, shy behavior via specific parenting practices. First, in the mediation model involving authoritative parenting as the mediator (see Figure 5), the results indicated that (a) parenting stress predicted authoritative parenting $\left(\Delta R^{2}=.17 ; F\right.$ Change $\left.=5.00 ; p<.05 ; \beta=-.41\right)$ and (b) authoritative parenting predicted inhibited, shy behavior $\left(\Delta R^{2}=.15 ; F\right.$ Change $\left.=4.36 ; p<.05 ; \beta=.42\right)$, when controlling for the contribution of parenting stress. Second, in the mediation model involving authoritarian parenting, the results indicated that (a) parenting stress predicted authoritarian parenting $\left(\Delta R^{2}=.18 ; F\right.$ Change $\left.=5.54 ; p<.05 ; \beta=.43\right)$ and $(\mathrm{b})$ authoritarian parenting predicted inhibited, shy behavior $\left(\Delta R^{2}=.28 ; F\right.$ Change $\left.=9.85 ; p<.01 ; \beta=-.59\right)$, when controlling for the contribution of parenting stress. Parenting stress did not predict overprotective parenting $\left(\Delta R^{2}\right.$ $=.002 ; F$ Change $=0.41 ; n s ; \beta=-.04$ ), however overprotective parenting did predict inhibited, shy behavior $\left(\Delta R^{2}=.16 ; F\right.$ Change $\left.=4.80 ; p<.05 ; \beta=.40\right)$. Given this evidence, a post hoc analyses was done to examine parenting stress as a moderator between parenting and inhibited, shy behavior.

\section{Moderation Models}

Regression analyses were conducted to examine (a) the separate contributions of parenting stress and parenting practices (authoritarian, authoritative, and overprotective) on inhibited, shy behavior; and (b) the moderated contribution of parenting stress on the relation between 
parenting practices and inhibited, shy behavior (Tables 3 and 4). To avoid multicollinearity, parenting stress, authoritarian, authoritative, and overprotective parenting were centered on their means before creating the interaction terms.

\section{Predictions of Inhibited, Shy Behavior}

Authoritarian parenting was a main effect predictor of inhibited, shy behavior $\left(\Delta R^{2}=.19\right.$;

F Change $=6.21 ; p<.05)$. An examination of the beta weight indicated that the relation between authoritarian parenting and inhibited, shy behavior was negative ( $\beta=-.44)$.

Authoritative parenting was a main effect predictor of inhibited, shy behavior $\left(\Delta R^{2}=.16\right.$; $\Delta F=4.87 ; p<.05)$. An examination of the beta weight indicated that the relation between authoritative parenting and inhibited, shy behavior was positive $(\beta=.40)$.

Overprotective parenting was a main effect predictor of inhibited, shy behavior $\left(\Delta R^{2}\right.$ $=.16 ; \Delta F=5.03 ; p<.05)$. An examination of the beta weight indicated that the relation between overprotective parenting and inhibited, shy behavior was positive $(\beta=.40)$. This main effect predictor was subsumed by an interaction effect; specifically, the interaction between parenting stress and overprotective parenting approached significance $\left(\Delta R^{2}=.10 ; \Delta F=3.14 ; p\right.$ $<$.09). The interaction was explored following the recommendations of Cohen, Cohen, West, and Aiken (2003). Specifically, for each interaction I restructured the equation to express the regression of the dependent variable (inhibited, shy behavior) on overprotective parenting for high and low parenting stress. As depicted in Figure 8, the simple slopes for the high levels of stress was significant (simple slopes $=2.53, p<.05$ ), whereas the simple slopes for the low 
levels of stress was (simple slopes $=0.65, n s$ ). 


\section{CHAPTER 5}

\section{DISCUSSION}

This study investigated the role of parenting stress in the development of children's inhibited, shy behavior. Specifically, this study examined the mediation mechanism among parenting stress, parenting practices, and child inhibited, shy behavior.

\section{Parenting Practices as Mediators}

To begin, it was expected that parenting practices would mediate the relation between parenting stress and inhibited, shy behavior in children. Specifically, it was expected that high levels of parenting stress would be significantly related to high levels of dysfunctional parenting (authoritarian and overprotective) which would predict inhibited, shy behavior in children. In addition, it was expected that parenting stress would negatively predict authoritative parenting, which would negatively predict inhibited, shy behavior. But, the mediation models were not supported in the current study. Specifically, parenting was not a mediator between parenting stress and children's inhibited, shy behavior. According to Baron and Kenny (1986), mediation is established by four steps: (a) The independent variable (parenting stress) should be significantly correlated with dependent variable (children's inhibited, shy behavior); (b) The independent variable (parenting stress) should be significantly correlated with mediators (parenting practices); (c) The mediators (parenting practices) should be significantly correlated with dependent variable (children's inhibited, shy behavior); and (d) When the mediator (parenting practices) is controlled, the correlation of between parenting stress and children's inhibited, shy behavior will not be significant any more. In the tested models, since the independent variable (parenting stress) did not significantly predict the dependent variable (children's inhibited, shy behavior), the test of meditation failed. It may be that most of the 
parents came from the middle class families, and did not face high levels of parenting stress which are known to influence children’s behavioral problems (e.g., Guajardo et al., 2009). Furthermore even when parents in the sample indicated some stress, it is likely that they had access to resources (e.g., social support) to decrease their stress levels, which likely buffered children from any impact of parenting stress (e.g., Abidin, 1992). Indeed, it may be that sample characteristics contributed to the inability to establish a relation between parenting stress and child inhibited, shy behavior.

However, based on Iacobucci, Saldanha, and Deng (2007), the results did indicate an indirect effect of parenting stress on children's inhibited, shy behavior via the parenting practices. Specifically, in the first and second tested model (see Figures 5 \& 6), the links were significant between: (a) independent variables (parenting stress) and mediators (authoritative and authoritarian parenting practice) and (b) mediators (authoritative and authoritarian parenting practice) and dependent variables (children's inhibited, shy behavior). So, it was concluded that parenting stress may indirectly influence the children's inhibited, shy behavior through the role of parenting practices. Specifically, in the tested model 1, when parents reported low levels of parenting stress, they engaged in higher levels of authoritative parenting than when parents reported high levels of parenting stress. It was expected that parents who reported low levels of stress would engage in high levels of sensitive, warm parenting, such as authoritative parenting, which would be predictive of low levels of inhibited, shy behavior in children. This hypothesis was partially supported in the study. That is, the results indicated that there was a negative relation between parenting stress and authoritative parenting. However, the link between authoritative parenting and inhibited, shy behavior was positive, which was contradictory to what was expected and the existing literature (see Rubin et al; 1997, 1999, 2002). It may be that this 
finding is an artifact of the use of the total scores of authoritative parenting. There are four subscales that comprise the larger construct of authoritative parenting in the $P P Q$ measure (Robinson et al., 1995), including scores of Warmth and Involvement, Reasoning/Induction, Democratic Participation, and Good Natural/Easy Going. It may be that the items from the Warmth and Involvement scale are responsible for this relation; indeed previous studies have reported that too much warm and involved parenting limits children's independence or self-efficacy (e.g., Rubin et al., 2002), and may be linked to the display of inhibited, shy behavior. In the future, it would be important to separately examine the individual subscales that comprise authoritative parenting to look at whether the differences might be there.

In addition, in the second tested model, the parents who reported high levels of stress reported higher levels of authoritarian parenting than those with low levels of parenting stress. This is consistent with the previous studies (e.g., Deater-Deckard, 1996; Guajardo, et al, 2009; Mills \& Rubin, 1990). However, this study found that when parents reported authoritarian parenting, their children were reported to display low levels of inhibited, shy behavior. This is consistent with the findings reported by Park et al. (1997) but is contradictory with previous studies (e.g., LaFreniere \& Dumas, 1992; Mills \& Rubin. 1990) that have supported that parents who engage in authoritarian parenting have children who are inhibited and shy. In this study, it may be that authoritarian parents pushed their inhibited, shy children to interact with their peers rather than control their behavior. Thus, it may be that as the parents urged their children to explore novel situations, their children were likely to gradually decrease their inhibited, shy behavior. In addition, the mean of authoritarian parenting was relatively low (see Table 1). Thus, it is important to stress that participants were possibly not comparable to those in other studies of parenting stress where harsh, abusive parenting was related to parenting stress (e.g., 
Chan, 1994; Erath et al., 2009).

\section{Parenting Stress as a Moderator}

Furthermore, since the hypothesized meditations were not supported, parenting stress was further examined as a moderator of the relation between parenting practices and inhibited, shy behavior. As noted above, authoritarian parenting was negatively predictive of inhibited, shy behavior, and authoritative parenting was positively predictive of inhibited, shy behavior (and, of course, these findings were also significant in the moderation models). Interestingly, in the moderation analyses, it was found that parenting stress moderated the relation between overprotective parenting and inhibited, shy behavior, but the same was not found for the models with the other parenting practices. In other words, parenting stress appears to exacerbate the relation between overprotective parenting and inhibited, shy behavior (see Figure 8). Thus, if overprotective mothers reported high levels of parenting stress, their children were more likely to indicate inhibited, shy behavior than those mothers that reported low levels of parenting stress. The reasons might be that when overprotective parents are highly stressed, they are likely to be anxious, which possibly makes parents more controlling of their children. Thus, this controlling parenting possibly further exacerbates their children’s inhibited, shy behavior (e.g., Rubin et al., 2002). Importantly, this is the first study to examine how parenting stress may moderate the relation between overprotective parenting practices and inhibited, shy behavior.

\section{The Role of Parenting Stress in the Development of Inhibited, Shy Behavior}

The findings from this study are exciting as it supports Rubin’s (1993) contention that parenting stress likely plays a role in the development of inhibited, shy behavior, and may be an important factor to consider in the development of psychopathology. Specifically, Rubin (1993) proposed that all families are faced with stress occurring regularly and intensively, which further 
influences the parent-child relationship, and the social and emotional well-being of children. Rubin (1993) considered that the underlying reasons for the relation between stress and dysfunctional parenting may be that stress, such as economic poverty, is often associated with parental conflict; in turn, conflict is associated with parental anger, insensitivity, inconsistency, and punitiveness in childrearing. Such dysfunctional parenting may be detrimental to the development of inhibited, shy behavior.

Rubin (1993) also argues that stress may lead to parental maladaptive response, such as neglect or overdirection which could further influence inhibited, shy behavior. In addition, according to Rubin (1993) parents of inhibited, shy children may already experience high levels of parenting stress because of their children's dispositions; therefore, if the parents also lack social support, they possibly become hostile, insensitive, and non-responsive to their wary babies.

Indeed, the findings herein support Rubin's (1993) suggestions for the relations between parenting stress, parenting practices, and inhibited, shy behavior. Specifically, the current study did find parenting stress indirectly influenced inhibited, shy behavior via parenting practices. That is parenting stress significantly predicted parenting practices and parenting practices also significantly predicted inhibited, shy behavior. In addition, this current study examined and confirmed parenting stress moderated the association between parenting (e.g., overprotective parenting) and inhibited shy behavior. Thus, it seems to support Rubin’s (1993) arguments, however further research is required to test a full mediation model, and to examine the longitudinal implications for these processes.

\section{Family System Theory}

The findings of this study may be best understood considering a family systems approach. 
Family system theory largely comes from von Bertalanffy's general system theory (1968) that proposed the basic principles can be used to understand different systems. He thought the principles of system theory are best understood when researchers pay attention to the interaction of system parts rather than the characteristics of individual parts of a system. Thus, a family system theory considers the behavior that goes on between system members, and does not solely focus on the individual traits or feelings of the members. This theory seems particularly relevant to this area of study, especially the three principles of family system theory: Wholeness, Interdependence, and Hierarchy. Wholeness refers to "individual parts of the system (i.e., family members) come together to form a whole” (Arnold, 2008, p. 63). In other words, family system goes beyond the individual members who consist of the system and it is a reflection of wholeness. Interdependence refers to "members or features of a system influence each other” (Arnold, 2008, p. 63). For example, when a child comes down with the flu, the sickness influences the parent or caretaker in a family, even if they do not become really sick physically. Thus, the behavior of one member in a system or one part in a system will affect other parts of that system. Hierarchy refers to there are smaller systems existing within a family systems (Arnold, 2008). For instance, inside a family system, there exist many sub-systems such as the marital system, the sibling system, parent and child systems. Therefore, researchers can focus their study on a particular sub-system.

In the current study, the sub-system of Parent and Child was examined (Hierarchy). In this system, when one part of the system, such as parent, was highly stressed, the other part of system, the child, was likely to be affected, and may express inhibited, shy behavior (Interdependence). As examined in the current study, this influence may be mediated by parenting practices. Specifically, it was hypothesized that stressed parents may endorse 
dysfunctional parenting practices (either authoritarian or overprotective) which would then in turn influence children's inhibited, shy behavior. The mediation model was not fully supported, however there were some findings that indicated that the family system was influenced by stress; moreover, post-hoc analyses indicated that the system was also impacted by stress as a moderator. Given these clear links with family systems theory, it would be prudent to further examine the family-level processes that may play a role in the development of inhibited, shy behavior.

\section{Limitations and Future Directions}

In this study, there were several limitations. First, the sample size was small, thus it is likely that analyses were not powerful enough to detect the relations among variables (as indicated in the trend-level findings). Based on previous literature, it is likely that a sample size of at least 100 would be needed to detect these relations. In addition, the sample was homogenous; for instance most of the participants were Caucasian, and most were from middle class families that presumably faced relatively low levels of parenting stress. In the future, researchers should recruit more heterogeneous samples, including African Americans, Asian Americans, and Native Americans, in order to see if the same relations between variables emerge. Moreover, and possibly more important, future researchers should make an effort to recruit from low SES families, as this type of sample possibly face higher levels of parenting stress than middle class families. If the same study was conducted in a sample with elevated parenting stress, it is possible that the relation between parenting stress and children's inhibited, shy behavior would emerge significant.

Indeed, it is likely that the participants were not really stressed, or were experiencing stress that is not measured by the PSI/SF. Better put, it has been theorized that contemporary, middle class families face a new type of stress which results from a lack of time and an emphasis 
to provide the best for children (Hewlett \& West, 2005). Specifically, parents from middle class, such as those in the present sample, may feel increased demand to be successful in the work arena in order to give the best to their children. Ironically, this likely decreases the amount of time they are able to spend with their children which is likely in contrast to the pressure to spend high quality time with their children. The combination of these two types of demands likely result in a type of parenting stress that is not be measured via the PSI/SF. Thus, it may be useful to test these models with a different measure that taps into this type of parenting stress. Furthermore, if parents were stressed, they were from a middle income sample and likely had more resources and support (Abidin, 1992); and thus they would be less likely to allow their stress to impact their children's behavior. Therefore, additional work is required with larger samples, samples that may be more prone to stress (e.g., low SES), and perhaps with different indices of parenting stress to see if these relations exist.

Second, there were no inclusion criteria for the present sample aside from age, health, and willingness to participate, thus they were not necessarily temperamentally inhibited, shy children. In the future, researchers should pre-select for behavioral inhibition; for example, Kagan et al. (2007) suggest that $15 \%$ of the population is behaviorally inhibited. It would be interesting to examine the processes examined in this study in a sample that was prescreened for inhibition (i.e., the top $15 \%$ of the population). It is possible that the parents of temperamentally inhibited, shy children would respond differently than the current sample because the parents of temperamentally inhibited children may face high levels of parenting stress related to the characteristics of their children (Rubin, 1993). It may be that the scores of “Difficult Child” subscale in the PSI/SF (e.g., child behavioral characteristics that are difficult to manage; “My child is not able to do as much as I expected.”) would be increased because of 
children's inhibited, shy behavior. Thus, I would expect that when parents know their child is fearful and anxious, they may report increased stress on the "Difficult Child” subscale. This specific type of stress may lead to increases in dysfunctional parenting, such as overprotective and authoritarian parenting. Moreover, in a pre-selected sample, the relation between high levels of parenting stress and children's inhibited, shy behavior may be significant, however it may be that behavioral inhibition predicts parenting stress. Indeed, this is an area of research ripe for future investigation.

Last but not least, data collection was through one single informant. Specifically, all data collection was by mothers' report, and thus was reflective only of mothers' perceptions of parenting stress, parenting practices, and children’s behaviors. It may be that mothers overestimate or underestimate their children's inhibited, shy behavior. Indeed drawing from the literature on maternal depression, it is known that when mothers are under distress they tend to view their children more negatively (e.g., Gelfand et al., 1992). In order to correct this bias, in the future, fathers' or other informants' data should be included in similar studies. Ideally, observational data could be collected in addition to parental report. Data collection could happen at home or in the laboratory where researchers are able to objectively rate parenting style and children's inhibited, shy behavior. The home observations would allow for a more authentic understanding of the relation between parenting stress, parenting practices, and the development of inhibited, shy behavior since parent-child interactions that take place in the home would provide a picture of these processes as they occur in the natural environment. It may be that observing parents and their children during mealtime interactions or during playtime that powerful indices of overcontrol or intrusiveness can be obtained. Moreover, data from teachers would be useful to include in future studies. Since preschool teachers spend a lot of time with 
children, they have a perspective of children that parents may not have, namely children's interactions with peers. Teachers are able to view interactions children have with one another, and are able to make ratings comparing children's behaviors to their peers. In addition, teachers' data are obtained from the school setting that represents a major social context for preschoolers. This is likely especially important when considering the development of inhibited, shy behavior, as inhibited, shy children are known to be at risk for rejection by peers (e.g., Gazelle \& Spangler, 2007). Thus, teachers are reliable assessors of children’s school behaviors in the preschool years. Such data are helpful for researchers to investigate the preschoolers' inhibited, shy behavior in the social environment.

\section{Conclusions}

This study is the one of the first studies to investigate the relations among parenting stress, parenting practice, and children's inhibited, shy behavior. This study serves to remind future researchers to further examine parenting stress and child development. The findings of the study are meaningful for the real world. Specifically, it seems that complicated patterns emerge when examining parenting as an influence on the development of inhibited, shy behavior. For example, although it was not expected that a functional form of parenting - authoritative parenting - was positively predictive of children's inhibited, shy behavior; this finding may have implications for intervention and prevention research. Although further research is required, it may be that parents who engage in overly warm and involved parenting, need to be reminded not to "smother" their children, as overly warm parenting may influences the development of inhibited, shy behavior (e.g., Rubin \& Burgess, 2002). Thus, parents should be encouraged to be involved with their children, but not too much, as enmeshment may worsen children's development. 
To complicate matters, certain forms of dysfunctional parenting were negatively associated with inhibited, shy behavior in preschoolers. Indeed, authoritarian parenting negatively predicted children's inhibited, shy behavior. This is not to say that parents should be harsh and punitive with their children in an effort to move them off a pathway of inhibition, but it is likely that parents need to engage in an appropriate amount of direction and control with their preschoolers. Thus, more research is required to better understand the levels of warmth and direction that are best to support the development of inhibited, shy children.

Furthermore, it was confirmed that parenting stress is a moderator between overprotection and children's inhibited shy behavior. Thus, it seems that stress does play a role in worsening the relation between overprotection and inhibited, shy behavior (e.g., Rubin, 1993). It is possible that parenting stress makes parents become anxious, and then they over direct or control their children's behavior. Since the parenting stress is common to each family, it is worth further investigating the role of parenting stress in parenting and the child development in the future.

In sum, the current study illustrates the powerful role that parenting practices, and the factors that impact parenting practices (e.g., stress), play in the development of inhibited, shy behavior. Indeed, the findings of this study are important because they provide an understanding of how parents may develop dysfunctional parenting practices via parenting stress and the implications of parenting stress on the development of inhibited, shy behavior. 


\section{References}

Abidin, R. R. (1983). Parenting Stress Index. Charlottesville, VA: Pediatric Psychology Press.

Abidin, R. R. (1986). Parenting Stress Index ( $\left.2^{\text {nd }} e d.\right)$. Charlottesville, VA: Pediatric Psychology Press.

Abidin, R. R. (1990). The Parenting Stress Index Short Form. Charlottesville, VA: Pediatric Psychology Press.

Abidin, R. R. (1990). Introduction to the special issue: the stress of parenting. Journal of Clinical Child Psychology, 19, 298-301.

Abidin, R. R. (1990). Parenting Stress Index. Charlottesville, VA: Pediatric Psychology Press.

Abdin, R. R. (1992). The determinants of parenting behavior. Journal of Clinical Child Psychology, 21, 407-412.

Abidin, R. R. (1995). Parenting Stress Index. Charlottesville, VA: Pediatric Psychology Press.

Abidin, R. R. (1995). Parenting stress index (PSI) manual (3rd ed.). Odessa, FL: Psychological Assessment Resources.

Abidin, R. R. (1997). Parenting Stress Index: A measure of the parenting- child system. In P. Z. Carlos \& J.W. Richard (Eds.), Evaluating stress: A book of resources (pp. 277-291). London, England: The Scarecrow Press.

Achenbach, T. M . (1991). Manual for the child behavior checklist and 1991 profile. Burlington, VT: Department of Psychiatry, University of Vermont.

Ainsworth, M. D. S., Blehar, M. C., Waters, E., \& Wall, S. (1978). Patterns of attachment: A psychological study of the strange situation. Hillsdale, NJ: Erlbaum.

Albrecht, J. L., \& Tomich, P. J. (1996). The maternal and neonatal outcome of triplet gestations. American Journal of Obstetrics and Gynecology, 174, 1551 - 1556. 
Anthony, L. G., Anthony, B. J., Glanville, D. N., Naiman, D. Q., Wannders, C., \& Shaffer, S. (2005). The relationships between parenting stress, parenting behavior and preschoolers' social competence and behavior problems in the classroom. Infant and Child

Development, 14, 133-154.

Arnold, D. S., O’Leary, S. G., Wolff, L. S., \& Acker, M. M. (1993). The parenting scale: A measure of dysfunctional parenting in discipline situations. Psychological Assessment, 5, 137-144.

Arnold, L. B. (2008). Family communication: Theory and research. Boston: Pearson Education.

Assel, M. A., Swank, P. R., Steelman, L., Miller-Loncar, C., \& Smith, K. E. (2002). How do mothers’ childrearing histories, stress and parenting affect children’s behavioral outcomes? Child: Care, Health \& Development, 28, 359-368.

Bell-Dolan, D., Reaven, N., \& Peterson, L. (1993). Depression and social functioning: A multidimensional study of the linkages. Journal of Clinical Child Psychology, 22, 306315.

Belsky, J. (1984). The determinants of parenting: A process model. Child Development, 55, 83-96.

Belsky, J., Putnam, S., \& Crnic, K. (1997). Coparenting, parenting, and early emotional development. New Directions in Child Development, 74, 45-56.

Biederman, J., Rosenbaum, J. F., Bolduc-Murphy, E. A., Faraone, S. V., Chaloff, J., Hirshfeld, D. R., \& Kagan, J. (1993). A 3-year follow-up of children with and without behavioral inhibition. Journal of the American Academy of Child and Adolescent Psychiatry, 32, 814-821.

Block, J. H. (1965). The child-rearing practices report: A technique for evaluating parental socialization orientations. Berkeley, CA: University Of California, Institute of Human 
Development.

Block, J. H. (1981). The Child-Rearing Practices Report (CRPR): A set of Q items for the description of parental socialization attitudes and values. Berkeley, CA: University of California, Institute of Human Development.

Bonds, D., \& Gondoli, D. M. (2002). Parenting stress as a mediator of relation between parenting support and optimal parenting. Parenting Science and Practice, 2, 409-435.

Brandt, P. A., \& Weintert, C. (1981). The PRQ-a social support measure. Nursing Research, 30, 277-280.

Baumrind, D. (1971). Current patterns of parental authority. Developmental Psychology Monographs, 4, 1-103.

Buss, A., \& Plomin, R. (1984). Temperament: Early developing personality traits. Hillsdale, NJ: Erlbaum.

Caspi, A., Moffitt, T. E., Newman, D. L., \& Silva, P. A. (1996). Behavioral observations at age 3 years predict adult psychiatric disorders. Archives of General Psychiatry, 53, 1033-1039.

Chan, Y. C. (1994). Parenting stress and social support of mothers who physically abuse their children in Hong Kong. Child Abuse \& Neglect, 18, 261-269.

Chandler, M. (1973). Egocentrism and antisocial behavior: The assessment and training of social perspective-taking skills. Developmental Psychology, 9, 326-332.

Cohen, J., Cohen, P., West, S. G., and Aiken, L. S. (2003). Applied Multiple Regression/ Correlation Analysis for the Behavioral Sciences. Mahwah, NJ: Lawrence Erlbaum.

Conger, R. D., Conger, K. J., Elder Jr, G. H., Lorenz, F. O. Simons, R. L., \& Whitbeck, L. B. (1992). A family process model of economic hardship and adjustment of early adolescent boys. Child Development, 63, 526-541. 
Conger, R. D, Patterson, G. R., \& Ge, X. (1995). It takes two to replicate: A Mediational Model for the Impact of parents’ stress on adolescent adjustment. Child Development, 66, 80-97.

Coplan, R., Prakash, K., O'Neil, K., \& Armer, M. (2004). Do you "want" to play? Distinguishing between conflicted shyness and social disinterest in early childhood. Developmental Psychology, 40, 244-258.

Crittendent, P. M. (1981). Abusing, neglecting, problematic and adequate dyads: Differentiating by patterns of interaction. Merrill-Palmer Quarterly, 27, 201-218.

Crnic, K. A., \& Low, C. (2002). Everyday stresses and parenting. In M. Bornstein (Eds.), The Handbook of Parenting: Practical Issues in Parenting (pp. 243-267). Mahwah, NJ: Erlbaum.

Crnic, K. A., Gaze, C., \& Hoffman, C. (2005). Cumulative parenting stress across the preschool period: Relations to maternal parenting and child behavior at age 5. Infant and Child Development, 14, 117-132.

Deater-Deckard, K. (1996). Parenting stress among dual-earner mothers and fathers: Are there gender differences? Journal of Family Psychology, 10, 45-59.

Deater-Deckard. K. (1998). Parenting stress and child adjustment: Some old hypotheses and new questions. Clinical Psychology: Science and Practice, 5, 314-332.

Denham, S., Bassett, H., \& Wyatt, T. (2007). The socialization of emotional competence. In J. E. Grusec, \& P. D. Hastings (Eds.), The handbook of socialization: Theory and research (pp. 614-637). New York, NY: Guilford.

Derogatis, L. R. (1983). SCL-90-R administration scoring, and procedures manual. Towson, MD: Clinical Psychometric Research.

Dohrenwend, B. S., Krasnoff, L., Askenasy, A. R., \& Dohrenwend, B. P. (1978). Exemplification 
of a method for scaling life events? The PERI Life Events Scale. Journal of Health and Social Behavior, 19, 205-229.

Early, D. M., Rimm-Kaufman, S. E., Cox, M. J., Saluja, G., Pianta, R. C., Bradley, R. H., \& Payne, C. C. (2002). Maternal sensitivity and child wariness in the transition to kindergarten. Parenting: Science and Practice, 2, 355-377.

Erath, S. A., El-Sheikh, M., \& Cummings, E. M., (2009). Harsh parenting and child externalizing behavior: Skin conductance level reactivity as a moderator. Child Development, 80, 578592.

Feldman, R., Eidelman, A. I., \& Rotenberg, N. (2004). Parenting stress, infant emotion regulation, maternal sensitivity, and the cognitive development of triplets: A model for parent and child influences in a unique ecology. Child Development, 75, 1774 - 1791.

Fox, N. A., \& Calkins, S. D. (1993). Pathways to aggression and social withdrawal: Interactions among temperament, attachment, and regulation. In K. H. Rubin, \& J. Asendorpf (Eds.), Social withdrawal, inhibition and shyness in children (pp. 81-100). Hillsdale, NJ: Erlbaum.

Garcia Coll, C., Kagan, J., \& Reznick, J. S. (1984). Behavioral inhibition in young children. Child Development, 55, 1005-1019.

Gauvin, M., \& Rogoff, B. (1989). Collaborative problem solving and children's planning skills. Developmental psychology, 25, 139-151.

Gazelle, H. (2006). Class climate moderates peer relations and emotional adjustment in children with an early history of anxious solitude: A child $\times$ environment model. Developmental Psychology, 42, 1179-1192.

Gazelle, H., \& Spangler, T. (2007). Early childhood anxious solitude and subsequent peer relationships: Maternal and cognitive moderators. Journal of Applied Developmental 
Psychology, 28, 513-535.

Gelfand, D. M., Teti, D.M., \& Fox, C. (1992). Sources of parenting stress for depressed and nondepressed mothers of infants. Journal of Clinical Child Psychology, 21, 262-272.

Goldsmith, H. H. (1988). The toddler behavior assessment questionnaire (Oregon center for the study of emotion technical report No. 88-04), Eugene, OR: University of Oregon.

Guajardo, N. R., Snyder, G., \& Petersen, R. (2009). Relationships among parenting practices, parental stress, child behavior, and children's social-cognitive development. Infant and Child Development, 18, 37-60.

Hewlett, S. A., \& West, C. (2005). The war against parents. In S. Olfman (Ed.), Childhood lost: $\quad$ How American culture is failing our kids (pp. 57 - 87). Westport, СT: Praeger.

Holden, E. W., \& Banez, G. A. (1996). Child abuse potential and parenting stress within maltreating parents. Journal of Family Violence, 1, 1-12.

Iaccobucci, D., Saldanha, N., \& Deng, X. (2007). A meditation on mediation: Evidence that structural equations models perform better than regressions. Journal of consumer psychology, 17, 140-154.

Kagan, J., Reznick, J., Clarke, C., Snidman, N., \& Garcia-Coll, C. (1984). Behavioral inhibition to the unfamiliar. Child Development, 55, 2212.

Kagan, J., Reznick, J. S., \& Snidman, N. (1987). The physiology and psychology of behavioral inhibition in children. Child Development, 58, 1459-1473.

Kagan, J., Snidman, N., Kahn, V., \& Towsley, S. (2007). The preservation of two infant temperaments into adolescence. Monographs of the Society for Research in Child Development, 72, 1-75.

Koeske G., \& Koeske, R. (1990). The buffering effect of social support on parental stress. 
American Journal of Orthopsychiatry, 60, 440-451.

Kuczynski, L., \& Kochanska, G. (1990). Development of children’s non-compliance strategies from toddlerhood to age 5. Developmental Psychology, 26, 378-408.

LaFreniere, P. J., \& Dumas, J. E. (1992). A transactional analysis of early childhood anxiety and social withdrawal. Development and Psychopathology, 4, 385-402.

Lawrence, E. C. (1982). The relationship between husband supportiveness and wife's adjustment to motherhood. Unpublished doctoral dissertation, University of Virginia, Charlottesville.

Lubin, B. (1963). Adjective checklists for measurement of depression. Archives of General Psychiatry, 12, 57-62.

Lyons-Ruth, K., Zoll, D., Connell, D., \& Grunebaum, H. U. (1986). The depressed mothers and her one-year-old infant: Environment, interaction, attachment, and infant development. In E. Z. Tronick \& T. Field (Eds.), Maternal depression and infant disturbance: Newdirections for child development (pp. 61-82). San Francisco: Jossey- Bass.

Mash, E., \& Johnston, C. (1990). Determinants of parenting stress: Illustrations from families of hyperactive children and families of physically abused children. Journal of Clinical Child Psychology, 19, 313-328.

Mead, G. H. (1934). Mind, self, and society. Chicago: University of Chicago Press.

Mills, R. S. L., \& Rubin, K. H. (1990). Parental beliefs about problematic social behaviors in early childhood. Child Development, 61, 138-151.

Muris, P., Merckelbach, H., Schmidt, H., Gadet, B., \& Bogie, N. (2001). Anxiety and depression as correlates of self-reported behavioural inhibition in normal adolescents. Behavior Research and Therapy, 39, 1051-1061.

Nelson, L. J., Hart, C. H., Olsen, S. F., \& Robinson, C. C. (2000, July). Behavioral and relational 
correlates of negative self-perceived competence in preschoolers. In R. Coplan \& H. Chen (Chairs), Recent issues in the study of inhibition, shyness, and social withdrawal in childhood. Symposium conducted at the XVIth biannual Meeting of the International Society for the Study of Behavioral Development, Beijing, China.

Ostberg, M., \& Hagekull, B. (2000). A structural modeling approach to the understanding of parenting stress. Journal of Clinical Child Psychology, 29, 615-625.

Park, S., Belsky, J., Putnam, S., \& Crnic, K. (1997). Infant emotionality, parenting, and 3-year inhibition: Exploring stability and lawful discontinuity in a male sample. Developmental Psychology, 33, 218-227.

Pascoe, J. M., Loda, F. A., Jeffries, V., \& Earp, J. A. (1981). The association between mothers' social support and provision of stimulation to their children. Developmental and Behavioral Pediatrics, 2, 15-19.

Piaget. J. (1928). Judgment and reasoning in the child. London: Routlege and Kegan Paul.

Putnam, S., \& Rothbart, M. (2006). Development of Short and Very Short Forms of the Children's Behavior Questionnaire. Journal of Personality Assessment, 87, 102-112.

Radloff, L. (1977). The CES-D Scale; A self-report depression scale for research in the general population. Applied Psychological Measurement, 1, 385-401.

Robinson, C. C., Mandleco, B., Olsen, S. F., \& Hart, C. H. (1995). Authoritative, authoritarian, and permissive parenting practices: Development of a new measure. Psychological Reports, 77, 819-830.

Rothbart, M. K., Ahadi, S. A., \& Hershey, K. L. (1994). Temperament and social behavior in childhood. Merrill-Palmer Quarterly, 40, 21-39.

Rothbart, M. K., Ahadi, S. A., Hershey, K. L., \& Fisher, P. (2001). Investigations of temperament 
at 3-7 years: The Children's Behavior Questionnaire. Child Development, 72, 1394-1408.

Rubin, K. H., \& Asendorpf, J. (1993). Social withdrawal, inhibition, and shyness in childhood: Conceptual and definitional issues. In K. H. Rubin \& J. Asendorpf (Eds.), Social withdrawal, inhibition and shyness in childhood (pp. 3-18). Hillsdale, NJ: Erlbaum.

Rubin, K. H., Bowker, J., \& Kennedy, A. (2008). Avoiding and withdrawing from the peer group. In K.H. Rubin, W. M. Bukowski, \& B. Laursen (Eds.), Handbook of peer interactions, relationships, and groups (pp. 303-321). New York: Guilford.

Rubin, K. H., \& Burgess, K. B. (2002). Parents of aggressive and withdrawn children. In M. Bornstein (Ed), Handbook of Parenting: Volume 1: Children and Parenting (pp. 383 -418). Mahwah, NJ: Erlbaum.

Rubin, K. H., Burgess, K. B., \& Hastings, P. D., (2002). Stability and social-behavioral consequences of toddlers' inhibited temperament and parenting behaviors. Child Development, 73, 483-495.

Rubin, K. H., Chen, X., McDougall, P., Bowker, A., \& McKinnon, J. (1995). The Waterloo Longitudinal Project: Predicting internalizing and externalizing problems in adolescence. Development and psychopathology, 7, 751-764.

Rubin, K. H., Coplan, R. J., Fox, N. A., \& Calkins, S. D. (1995). Emotionality, emotion regulation, and preschoolers' social adaptation. Development and psychopathology, 7, 49-62.

Rubin, K.H., Daniels-Beirness, T., \& Bream, L. (1984). Social isolation and social problem solving: A longitudinal study. Journal of Consulting and Clinical Psychology, 52, 17-25.

Rubin, K. H., Hastings, P. D., Stewart, S. L., Henderson, H. A., \& Chen, X.Y. (1997). The consistency and concomitants of inhibition: Some of the children, all of the time. Child 
Development, 68, 467-483.

Rubin, K. H., Nelson, L. J., Hastings, P., \& Asendorpf, J. (1999). The transaction between parents’ perceptions of their children’s shyness and their parenting styles. International Journal of Behavioral Development, 23, 937-957.

Scarpa, A., Raine, A., Venables, P., \& Mednick, S. (1997). Heart rate and skin conductance in behaviorally inhibited Mauritian children. Journal of Abnormal Psychology, 106,182-190.

Shamir-Essakow, G., Ungerer, J. A., \& Rapee, R. M. (2004). Caregiving representation of mothers of behaviorally inhibited and uninhibited preschool children. Developmental Psychology, 40, 899-910.

Stifter, C. A, \& Grant, W. (1993). Infant response to frustration: Individual differences in the expression of negative affect. Journal of Nonverbal Behavior, 17, 187-204.

Von Bertalanffy, L. (1986). General systems theory. New York: Braziller.

Webster-Stratton, C., \& Hammond, M. (1988). Maternal depression and its relationship to life stress, perceptions of child behavior problems, parenting behaviors, and child conduct problems. Journal of Abnormal Child Psychology, 16, 299-315. 
Table 1

Means and Standard Deviations of Independent Variables and Dependent Variables

\begin{tabular}{llllll}
\hline Variable & $n$ & $M$ & $S D$ & Min & Max \\
\hline
\end{tabular}

Independent Variables

$\begin{array}{lccccc}\text { Authoritarian Parenting } & 27 & 1.83 & 0.27 & 1.37 & 2.42 \\ \text { Authoritative Parenting } & 27 & 4.11 & 0.34 & 3.22 & 4.67 \\ \text { Overprotective Parenting } & 27 & 2.30 & 0.47 & 1.50 & 3.30 \\ \text { Parenting Stress } & 27 & 1.94 & 0.32 & 1.39 & 2.61\end{array}$

Dependent Variable

Inhibited/Shy Behavior

$\begin{array}{lllll}27 & 43.93 & 8.12 & 29.00 & 59.00\end{array}$


Table 2

Correlations Between Independent \& Dependent Variables

\begin{tabular}{|c|c|c|c|c|c|}
\hline & 1 & 2 & 3 & 4 & 5 \\
\hline \multicolumn{6}{|l|}{ Independent Variables } \\
\hline 1. Parenting Stress Total & -- & $0.42 *$ & $-0.41^{*}$ & -0.04 & -0.16 \\
\hline 2. Authoritarian & & -- & $-0.55 * *$ & -0.15 & $-0.55^{* *}$ \\
\hline 3. Authoritative & & & -- & 0.31 & $0.42 *$ \\
\hline 4. Overprotective & & & & -- & $0.40 *$ \\
\hline \multicolumn{6}{|l|}{ Dependent Variable } \\
\hline 5. Inhibited/Shy Behavior & & & & & -- \\
\hline
\end{tabular}

Note. $n=27 ;{ }^{*} p<.05$, two-tailed. ${ }^{* *} p<.01$, two-tailed 
Table 3

Mediation Analyses

Authoritative Parenting

Independent Variables

1. Parenting Stress

2. Parenting Stress, Authoritative

$\begin{array}{ll}\mathrm{R} & \Delta \mathrm{R}^{2} \\ 0.41 & 0.17^{*}\end{array}$

$0.41 \quad 0.17 * \quad-0.41$

Inhibited, Shy Behavior

Parenting

$--\quad--$

$--$

0.42

$0.15^{*} \quad 0.42$

Inhibited, Shy Behavior

\begin{tabular}{lcccccc} 
& $\mathrm{R}$ & $\Delta \mathrm{R}^{2}$ & $\beta$ & $\mathrm{R}$ & $\Delta \mathrm{R}^{2}$ & $\beta$ \\
\hline $\begin{array}{l}\text { 1. Parenting Stress } \\
\text { 2. Parenting Stress, Authoritarian }\end{array}$ & 0.43 & $0.18^{*}$ & 0.42 & 0.16 & 0.03 & -0.16 \\
$\quad$ & & & & & & \\
Parenting & -- & -- & -- & 0.56 & $0.28^{*}$ & -0.59 \\
\end{tabular}

Inhibited, Shy Behavior

Overprotective Parenting

$$
\mathrm{R} \quad \Delta \mathrm{R}^{2} \quad \beta
$$

$\mathrm{R} \quad \Delta \mathrm{R}^{2} \quad \beta$

1. Parenting Stress

$\begin{array}{lll}0.04 & .002 \quad-0.40\end{array}$

0.16

0.03

$-0.16$

2. Parenting Stress, Overprotective

Parenting

$--\quad--\quad--$
0.43
$0.16^{*} \quad 0.40$

Note 1. Reflects the first step entered in the regression equation (parenting stress). Note 2. Reflects the second step in the regression parenting practices while controlling for parenting stress. 
Table 4

Moderation Models

Inhibited/Shy Behavior

\begin{tabular}{|c|c|c|c|}
\hline Independent Variables/Interactions & $\mathrm{R}$ & $\Delta \mathrm{R}^{2}$ & $\beta$ \\
\hline Authoritative & 0.42 & $0.18^{*}$ & 0.42 \\
\hline Parenting Stress & 0.42 & .000 & 0.01 \\
\hline Authoritative X Parenting Stress & 0.43 & .008 & -0.09 \\
\hline Authoritarian & 0.55 & $0.30 *$ & -0.55 \\
\hline Parenting Stress & 0.56 & .007 & 0.09 \\
\hline Authoritarian X Parenting Stress & 0.57 & 0.02 & -0.15 \\
\hline Overprotective & 0.40 & $0.16^{*}$ & 0.40 \\
\hline Parenting Stress & 0.43 & 0.02 & -0.14 \\
\hline Overprotective X Parenting Stress & 0.53 & $0.10^{\mathrm{t}}$ & 0.34 \\
\hline
\end{tabular}

Note. $* p<.05$ 
Figure 1. Model of Theorized Paths of Influence on Parenting Behaviors and Child Outcomes (Abidin, 1976)

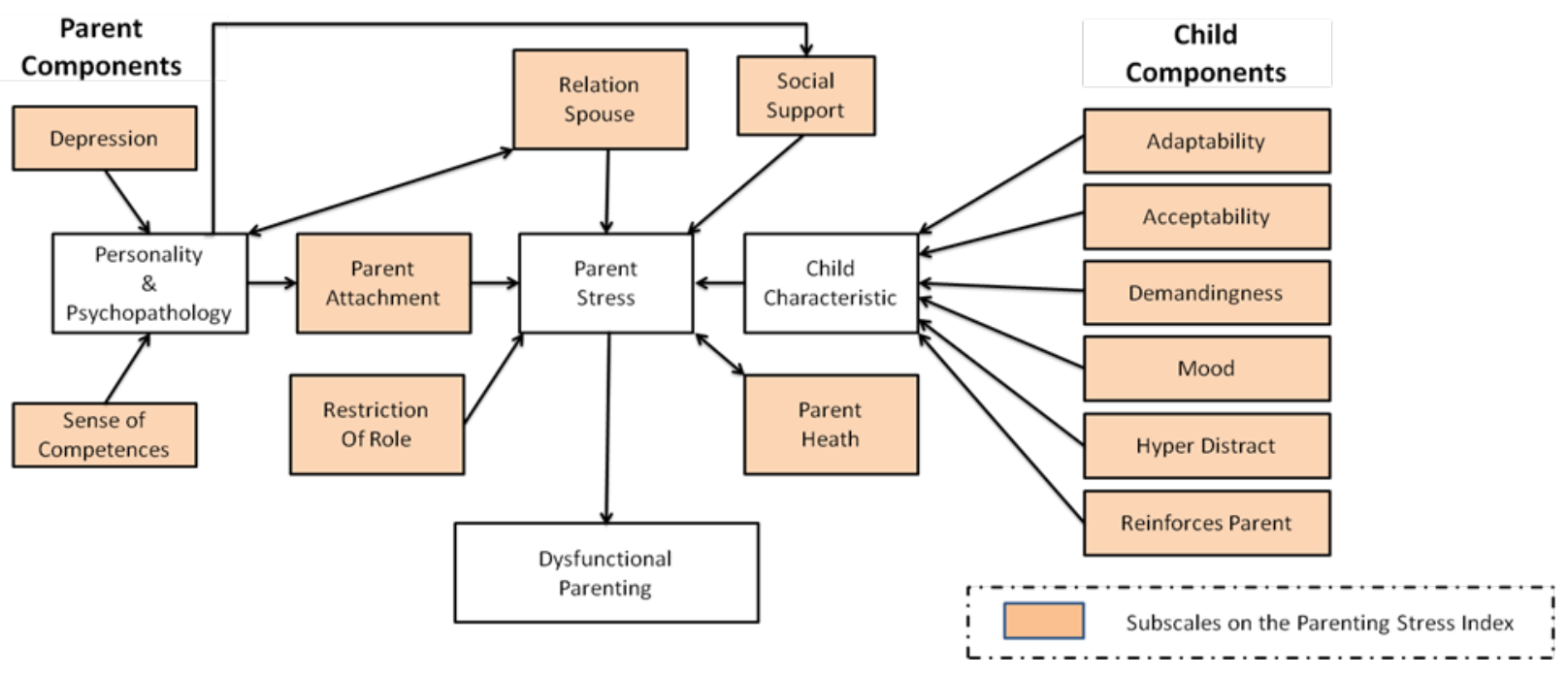


Figure 2. The Theorized Paths of Influence Regarding the Determinants of Parenting Behavior (Abidin, 1992)

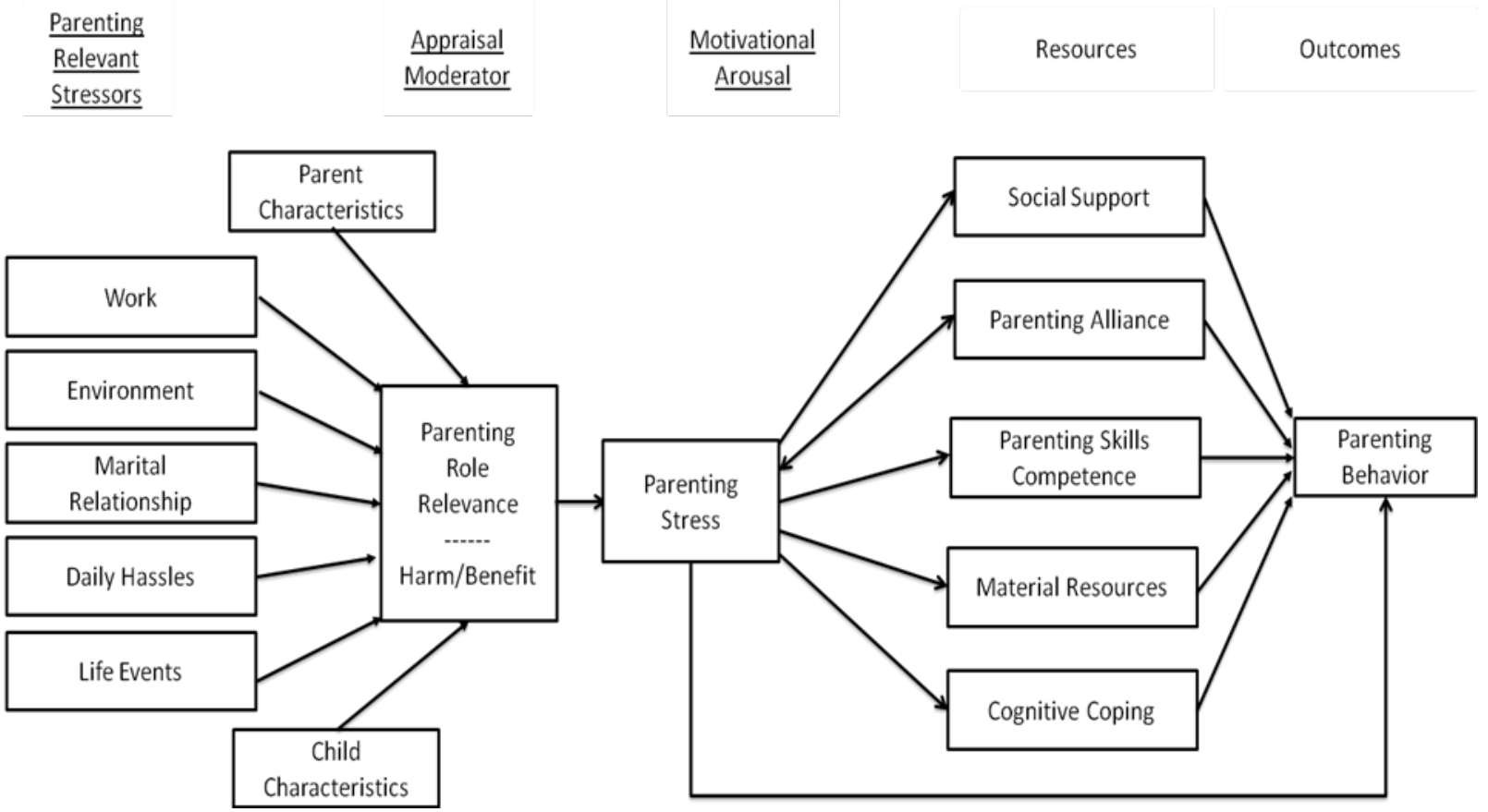


Figure 3. The Process Model of the Determinants of Parenting (Belsky, 1984)




Figure 4. Theoretical Mediation Model

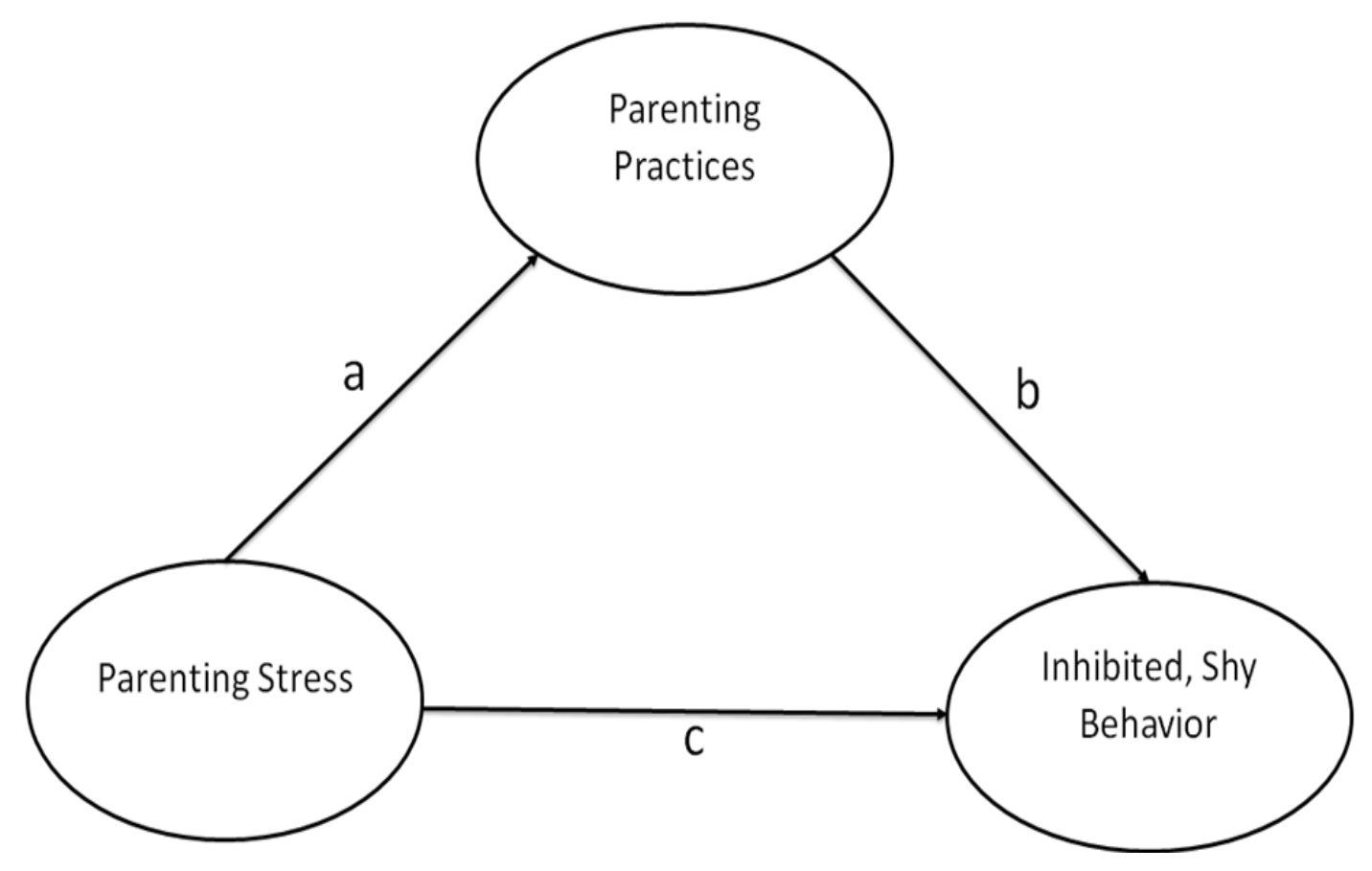


Figure 5. Tested Model 1




Figure 6. Tested Model 2




Figure 7. Tested Model 3

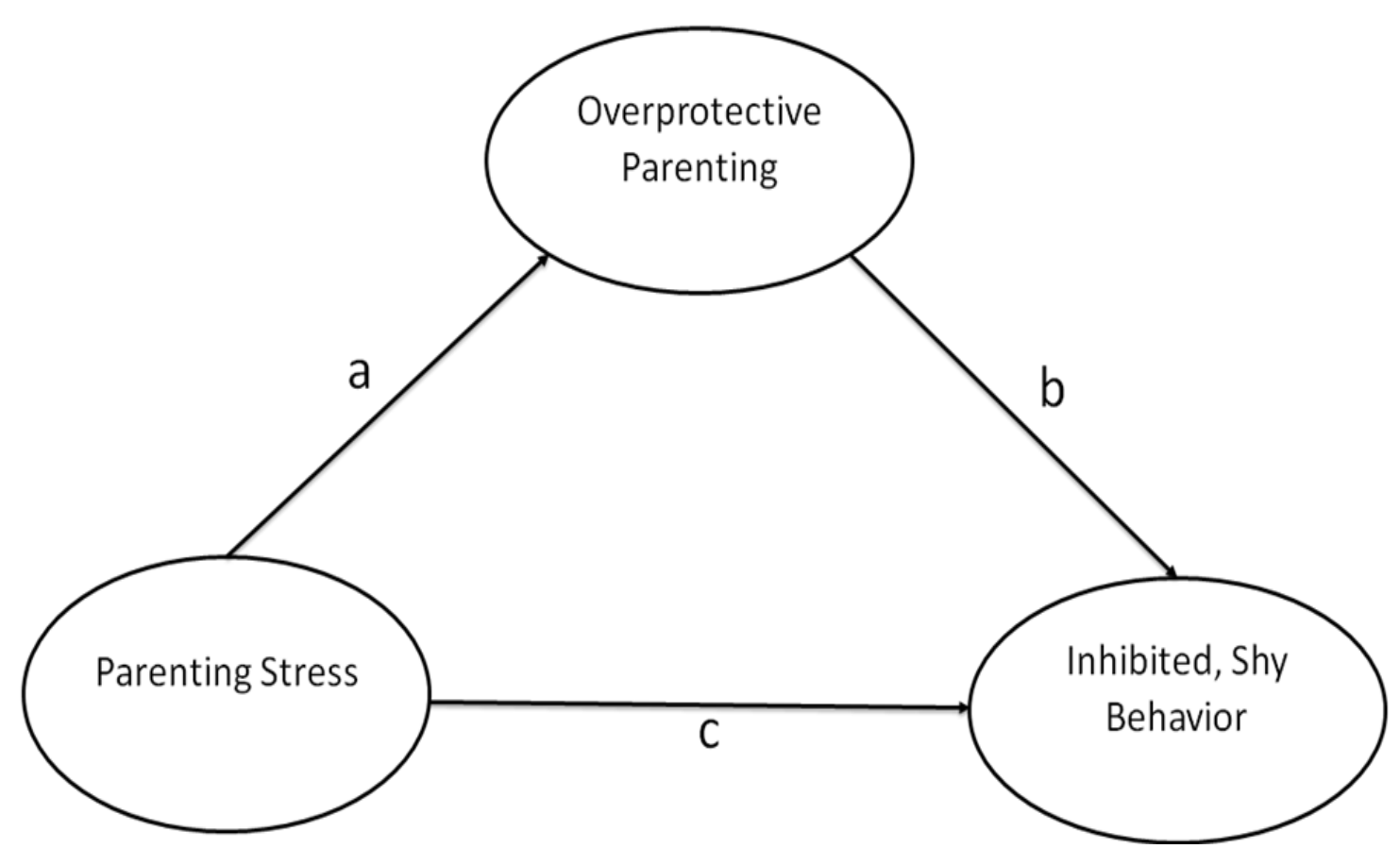


Figure 8. Inhibited, Shy Behavior as a Function of Overprotective Parenting at Levels of Parenting Stress

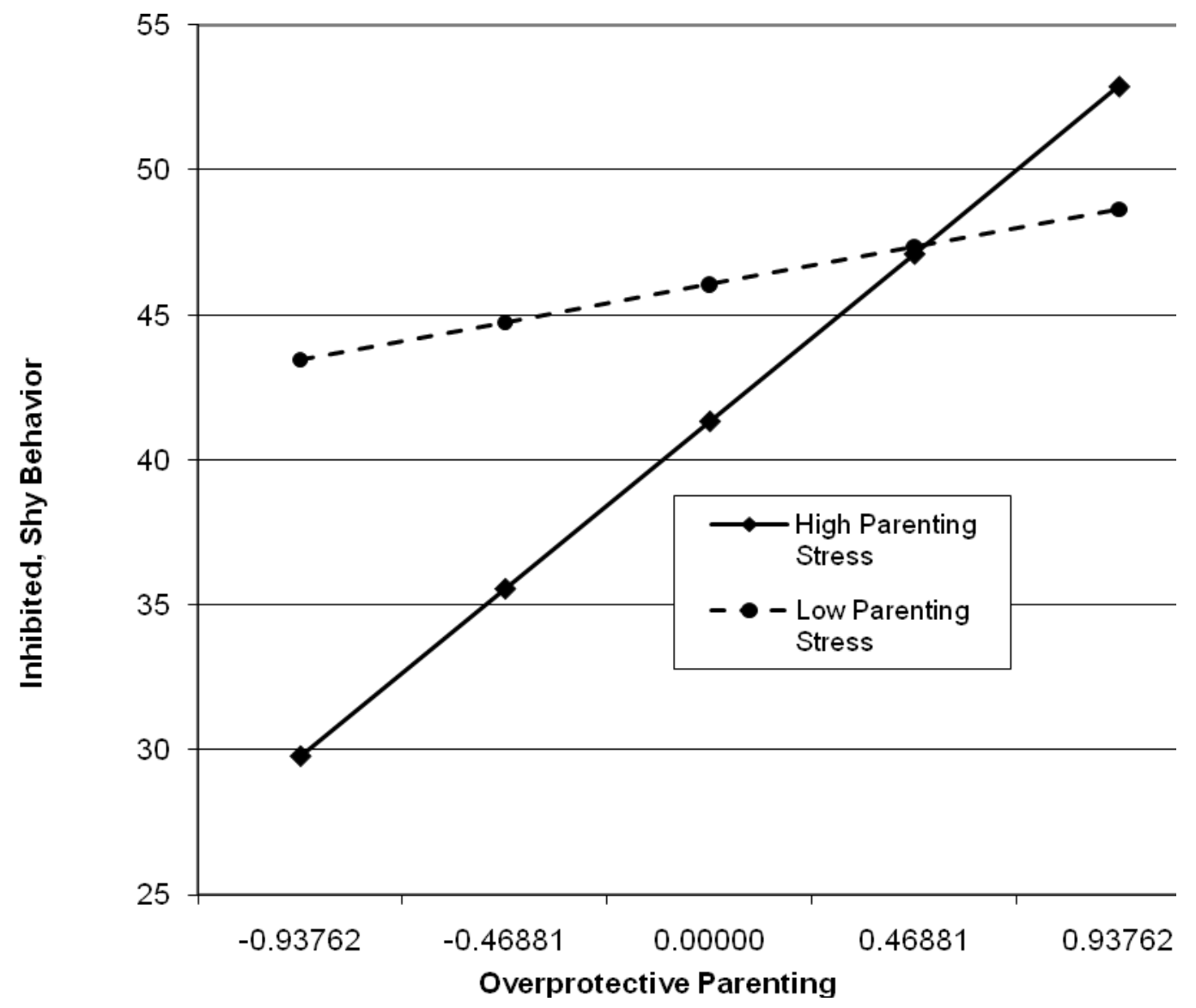




\section{APPENDIX A}

Demographic Information

Child's Birth date Child's Age

Month Day $\quad$ Year

Child's Sex (circle one): $\quad$ MALE $\quad$ FEMALE

Child's Country of Birth

Is your child biological? Adopted? Foster child?

Child's Ethnicity (circle one):

Hispanic or Latino

Not Hispanic or Latino

\section{Child's Race (check one):}

American Indian/Alaska Native

Asian

Black or African American

Native Hawaiian or Other Pacific Islander

White or Caucasian

Bi- or Multi-racial (please specify):

Other (please specify): 
Mother's Birthdate Age

Month Day Year

\section{Occupation}

What the mother's employment status:

$$
\begin{aligned}
& \text { Employed full-time } \\
& \text { Employed part-time } \\
& \text { Not employed outside of home } \\
& \text { Retired } \\
& \text { Unemployed } \\
& \text { Other (specify) }
\end{aligned}
$$

Mother's education level: $\quad$ Elementary School

High School

Vocational School

Some College

University Degree

Some Graduate School

Master's Degree

Doctoral Degree

Other (specify)

Mother's country of birth

If mother was not born in the U.S., how long has she been residing in the U.S.?

0 to 1 year

1 to 3 years

3 to 5 years

5 to 10 years over 10 years

Other

\section{Mother's Ethnicity (circle one):}

Hispanic or Latino

Not Hispanic or Latino

\section{Mother's Race (check one):}

American Indian/Alaska Native

Asian

Black or African American 
Native Hawaiian or Other Pacific Islander

White or Caucasian

Bi- or Multi-racial (please specify):

Other (please specify):

What language is spoken most often in your home?

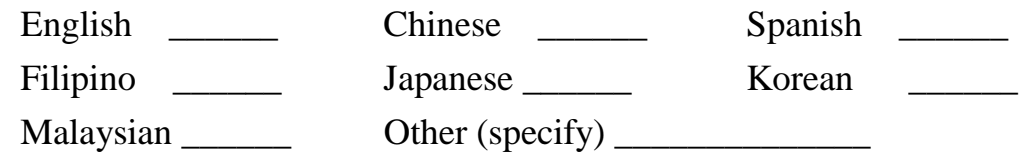

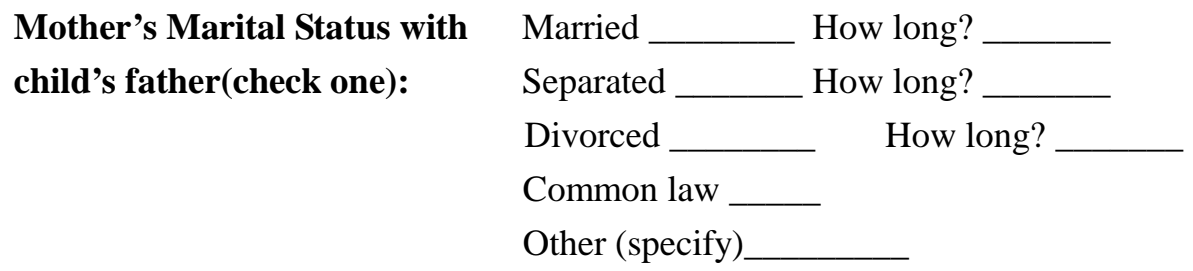

Mother's current relationship status (check one):

Married

Separated

Divorced

Common law

Single

Living with partner

Other (specify)

Child's Father's Birth date

Month

Day

Age

\section{Occupation}

What is the father's employment status:

Employed full-time

Employed part-time

Not employed outside of home

Retired

Unemployed

Other (specify) 
Father's education level: $\quad$ Elementary School

High School

Vocational School

Some College

University Degree

Some Graduate School

Master's Degree

Doctoral Degree

Other (specify)

Father's country of birth

If father was not born in the U.S., how long has he been residing in the U.S.?

0 to 1 year

1 to 3 years

3 to 5 years

5 to 10 years

over 10 years

Other

\section{Father's Ethnicity (circle one):}

Hispanic or Latino

Not Hispanic or Latino

\section{Father's Race (check one):}

American Indian/Alaska Native

Asian

Black or African American

Native Hawaiian or Other Pacific Islander

White or Caucasian

Bi- or Multi-racial (please specify):

Other (please specify): 
Father's Marital Status with child's mother (check one):

Married How long?

Separated How long?

Divorced How long?

Common law

Other (specify)

Father's current relationship status (check one):

Married

Separated

Divorced

Common bw

Single

Living with partner

Other (specify)

\section{Household Income:}

Less than $\$ 10,000$

$\$ 10,000$ - $\$ 25,000$

$\$ 25,000$ - $\$ 50,000$

$\$ 50,000$ - $\$ 75,000$

$\$ 75,000$ - $\$ 100,000$

$\$ 100,000$ - \$150,000

Greater than \$150,000 


\section{APPENDIX B \\ Parenting Stress Index/ Short Form Instructions}

This questionnaire contains 36 statements. Read each statement carefully. For each statement, please focus on the child you are most concerned about, and circle the response that best represented your opinion.

Circle the SA if you strongly agree with the statement.

Circle the $\mathbf{A}$ if you agree with the statement.

Circle the NS if you are not sure.

Circle the $\mathbf{D}$ if you disagree with the statement.

Circle the SD if you strongly disagree with the statement.

For example, if you sometimes enjoy going to the movies, you would circle $\mathbf{A}$ in response to the following statement:

I enjoy gong to he novies. SA A NS D SD

While you may not find a response that exactly states your feelings, please circle the response that comes closest to describing how you feel. YOUR FIRST REACTION TO EACH QUESTION SHOULD BE YOUR ANSWER.

Circle only one response for each statement, and respond to all statements. DO NOT ERASE! If you need to change an answer, make an " $\mathrm{X}$ " through the incorrect answer and circle the correct response. For example:

I enjoy going to he movies. SA A NS D SD

Before responding to the statements, write your name, gender, date of birth, ethnic group, marital status, child's name, child's gender, child's date of birth, and today's date in the spaces at the top of the questionnaire.
SA= Strongly Agree
A= Agree
NS $=$ Not Sure
$\mathrm{D}=$ Dsagree
$\mathrm{SD}=$ Strongly Disagree

1. I often have the feeling that I cannot handle hings very well.
SA
A NS
D
SD

2. I fnd myself giving up mre of my lfe $\mathrm{o}$ meet my dildren's neds han I ever expected.
SA
A
NS
D
SD

3. I fel rapped bymy esponsibilities $\mathbf{\Phi}$ a paent.
SA
A
NS
D
SD

4. Snce having his hild, Ihave ben urable o donew and dfferent hings.
SA
A
NS
D
SD

5. Snce having a hild, I feel hat I am dmost never ble $\mathrm{b}$ do hings hat I lke $\mathrm{b}$ do. 
SA $\quad$ A $\quad$ NS $\quad$ D $\quad$ SD

6. I am unhappy with the last purchase of clothing I made for myself.

SA $\quad$ A $\quad$ NS $\quad$ D $\quad$ SD

7. There ae quite a fw hings hat boher ne bout my lfe.

SA $\quad$ A $\quad$ NS $\quad$ D $\quad$ SD

8. Having a child has caused more problems than I expected in my relationship with my spouse (or male/female fiend).

SA $\quad$ A $\quad$ NS $\quad$ D $\quad$ SD

9. I feel done and without fiends.

$\begin{array}{lllll}\text { SA } & \text { A } & \text { NS } & \text { D } & \text { SD }\end{array}$

10. When I go đ a paty, I usially expect not $\mathrm{b}$ eijoy myself.

SA $\quad$ A $\quad$ NS $\quad$ D $\quad$ SD

11. I am not as interested in people as I uæd $\mathrm{t}$ be

SA $\quad$ A $\quad$ NS $\quad$ D $\quad$ SD

12. I don’t enjoy things as used to.

SA $\quad$ A $\quad$ NS $\quad$ D $\quad$ SD

13. My hild arely dos hings fr ne hat make ne feel good.

SA $\quad$ A $\quad$ NS $\quad$ D $\quad$ SD

14. Sometimes I feel my hild doesn’t lke ne and dosn't want $\mathrm{t}$ be dose $\mathrm{t}$ ne.

SA $\quad$ A $\quad$ NS $\quad$ D $\quad$ SD

15. My child smiles at me much less than I expected.

SA $\quad$ A $\quad$ NS $\quad$ D $\quad$ SD

16. When I do things for my child, I get the feeling that my efforts are not appreciated very much.

SA $\quad$ A $\quad$ NS $\quad$ D $\quad$ SD

17. When phying, my dild dosn't ofen gggle or bugh.

SA $\quad$ A $\quad$ NS $\quad$ D $\quad$ SD

18. My child doesn't seem to learn as quickly as most children. 
SA $\quad$ A $\quad$ NS $\quad$ D $\quad$ SD

19. My hild doen’t sem o smile $\$$ mich $\Phi$ most hildren.

SA $\quad$ A $\quad$ NS $\quad$ D $\quad$ SD

20. My child is not able to do as much as I expected.

SA $\quad$ A $\quad$ NS $\quad$ D $\quad$ SD

21. It takes a long time and it is very hard for my child to get used to new things.

SA $\quad$ A $\quad$ NS $\quad$ D $\quad$ SD

For the next statement, choose your response from the choices " 1 " to "5" below.

22. I feel that I am:

1. not very good at being a parent

2. a person who has some trouble being a parent

3. an average prent

4. a better than average parent

5. a very good parent

$\begin{array}{lllll}1 & 2 & 3 & 4 & 5\end{array}$

23. I expected o have doser and warmer felings for my child han I do ad his bohers me.

SA $\quad$ A $\quad$ NS $\quad$ D $\quad$ SD

24. Sometimes my child does things that bother me just to be mean.

SA $\quad$ A $\quad$ NS $\quad$ D $\quad$ SD

25. My hild sems to ay or fiss more ofen han most hildren.

SA $\quad$ A $\quad$ NS $\quad$ D $\quad$ SD

26. My child generally wakes up in a bad mood.

SA $\quad$ A $\quad$ NS $\quad$ D $\quad$ SD

27. I feel that my child is very moody and easily upset.

SA $\quad$ A $\quad$ NS $\quad$ D $\quad$ SD

28. My child does a few things which bother me a great deal.

SA $\quad$ A $\quad$ NS $\quad$ D $\quad$ SD

29. My child reacts very strongly when something happens that my child doesn’t like. 
SA $\quad$ A $\quad$ NS $\quad$ D $\quad$ SD

30. My child gets upset easily over the smallest thing.

SA $\quad$ A $\quad$ NS $\quad$ D $\quad$ SD

31. My child's sleeping or eating schedule was much harder to establish than I expected.

SA $\quad$ A $\quad$ NS $\quad$ D $\quad$ SD

For he rext satement, hoose your response from he choices “P” " $\mathrm{b}$ “' below.

32. I have found that getting my child to do something or \$op dong smething $\dot{\mathrm{s}}$ :

$\begin{array}{lllll}1 & 2 & 3 & 4 & 5\end{array}$

1. much harder than I expected

2. somewhat harder than I expected

3. about as hard as I expected

4. somewhat easier than I expected

5. much easier than I expected

For the next statement, choose your response from the choices "10+" to "1-3".

33. Think carefully and count the number of things which your child does that bother you.

$10+\quad 8-9 \quad 6-7 \quad 4-5 \quad 1-3$

For example: dawdles, refuses o Isten, overactive, aries, nterrupts, fghts, whines, Æc.

34. There are some things my child does that really bother me a lot.

SA $\quad$ A $\quad$ NS $\quad$ D $\quad$ SD

35. My child turned out to be more of a problem than I had expected.

SA $\quad$ A $\quad$ NS $\quad$ D $\quad$ SD

36. My child makes more demands on me han nost hildren.

SA $\quad$ A $\quad$ NS $\quad$ D $\quad$ SD 


\section{APPENDIX C}

\section{PARENTING PRACTICES QUESTIONNAIRE}

Make one rating for each item, rate how often you exhibit this behavior with your child

I Exhibit This Behavior:

1=Never
2=Once in Awhile
$3=$ About Half of the Time
$4=$ Very Often
$5=$ Always

1. I encourage my child to talk about the child's troubles.

2. I guide my child by punishment more than by reason.

3. I know the names of my child's friends.

4. I find it difficult to discipline my child.

5. I give praise when my child is good.

6. I spank when my child is disobedient.

7. I joke and play with my child.

8. I withhold scolding and / or criticism even when my child acts contrary to my wishes.

9. I show sympathy when my child is hurt or frustrated.

10. I punish by taking privileges away from my child with little if any explanation.

11. I spoil m child.

12. I give comfort and understanding when my child is upset.

13. I yell or shout when my child misbehaves.

14. I am easy going and relaxed with my child.

15. I allow my child to annoy someone else.

16. I tell my child my expectations regarding behavior before the child engages in an activity. 
17. I scold and criticize to make my child improve.

18. I show patience with my child.

19. I grab my child when being disobedient.

20. I state punishments to my child and do not actually do them.

21. I am responsive to my child's feelings or needs.

22. I allow my child to give input into family rules.

23. I argue with my child.

24. I appear confident about parenting abilities.

25. I give my child reasons why rules should be obeyed.

26. I appear to be more concerned with own feelings than with my child's feelings.

27. I tell my child that we appreciate what the child tries or accomplishes.

28. I punish by putting my child off somewhere alone with little if any explanation.

29. I help my child to understand the impact of behavior by encouraging my child to talk about the consequences of own actions.

30. I am afraid that disciplining my child for misbehavior will cause the child not to like her/ his parents.

31. I take my child's desires into account before asking the child to do something.

32. I explode in anger towards my child.

33. I am aware of problems or concerns abut my child in school.

34. I threaten my child with punishment more often than actually giving it.

35. I express affection by hugging, kissing, and holding my child.

36. I ignore my child's misbehavior.

37. I use physical punishment as a way of disciplining my child.

38. I carry out discipline after my child misbehaves.

39. I apologize to my child when making a mistake in parenting.

40. I tell my child what to do.

41. I give in to my child when the child causes a commotion about something. 
42. I talk it over and reason with my child when the child misbehaves.

43. I slap my child when the child misbehaves.

44. I disagree with my child.

45. I allow my child to interrupt others.

46. I have warm and intimate times together with my child.

47. When two children are fighting, I discipline the children first and ask questions later.

48. I encourage my child to freely express herself/himself even when disagreeing with parents.

49. I bribe my child with rewards to bring about compliance.

50. I scold or criticize when my child's behavior doesn't meet my expectation.

51. I show respect for my child's opinions by encouraging my child to express them.

52. I set strict well-established rules for my child.

53. I explain to my child how I feel about my child's good and bad behavior.

54. I use threats as punishment with little or no justification.

55. I take into account my child's preferences in making plans for the family.

56. When my child asks why s/he has to conform, I state: because I said so, or I am your parent and I want you to .

57. I appear unsure on how to solve my child's misbehavior.

58. I explain the consequences of the child's behavior.

59. I demand that my child does things.

60. I channel my child's misbehavior into a more acceptable activity.

61. I shove my child when the child is disobedient.

62. I emphasize the reasons for rules.

63. I ntervene if there is a chance that my child will fail at something.

64. I get anxious when my child tries to do something new or difficult for him/her.

65. I feel guilty when my child does not measure up to his/her potential.

66. I am fearful that others will not think well of my child. 
67. I try to control much of what my child does.

68. I think it is important to supervise all of my child's activities.

69. I discourage my child from trying new things if there is a chance my child will fail.

70. I expect my child to be close by when playing.

71. I tend to be overly involved in my child's activities.

72. I tend to be overly protective with my child. 


\section{APPENDIX D}

\section{Children's Behavior Questionnaire}

\section{Short Form Version I}

\section{Instructions: $\quad$ Please read carefully before starting:}

On the next pages you will see a set of statements that describe children's reactions to a number of situations. We would like you to tell us what your child's reaction is likely to be in those situations. There are of course no "correct" ways of reacting; children differ widely in their reactions, and it is these differences we are trying to learn about. Please read each statement and decide whether it is a "true" or "untrue" description of your child's reaction within the past six months. Use the following scale to indicate how well a statement describes your child:

Circle \# If the statement is:

l extremely untrue of your child

2 quite untrue of your child

3 slightly untrue of your child

4 neither true nor false of your child

5 slightly true of your child

$6 \quad$ quite true of your child

7 extremely true of your child

If you cannot answer one of the items because you have never seen the child in that situation, for example, if the statement is about the child's reaction to your singing and you have never sung to your child, then circle NA (not applicable). 
Please be sure to circle a number or NA for every item.

1. Seems always in a big hurry to get from one place to another.

$\begin{array}{llllllll}\mathrm{l} & 2 & 3 & 4 & 5 & 6 & 7 & \mathrm{NA}\end{array}$

2. Gets angry when told s/he has to go to bed.

$\begin{array}{llllllll}1 & 2 & 3 & 4 & 5 & 6 & 7 & \text { NA }\end{array}$

3. Is not very bothered by pain.

$\begin{array}{llllllll}1 & 2 & 3 & 4 & 5 & 6 & 7 & \text { NA }\end{array}$

4. Likes going down high slides or other adventurous activities.

$\begin{array}{llllllll}1 & 2 & 3 & 4 & 5 & 6 & 7 & \text { NA }\end{array}$

5. Notices the smoothness or roughness of objects s/he touches.

$\begin{array}{llllllll}1 & 2 & 3 & 4 & 5 & 6 & 7 & \text { NA }\end{array}$

6. Gets so worked up before an exciting event that s/he has trouble sitting still.

$$
\begin{array}{llllllll}
1 & 2 & 3 & 4 & 5 & 6 & 7 & \text { NA }
\end{array}
$$

7. Usually rushes into an activity without thinking about it.

$\begin{array}{llllllll}1 & 2 & 3 & 4 & 5 & 6 & 7 & \text { NA }\end{array}$

8. Cries sadly when a favorite toy gets lost or broken.

$$
\begin{array}{llllllll}
1 & 2 & 3 & 4 & 5 & 6 & 7 & \text { NA }
\end{array}
$$

9. Becomes quite uncomfortable when cold and/or wet.

$$
\begin{array}{llllllll}
1 & 2 & 3 & 4 & 5 & 6 & 7 & \text { NA }
\end{array}
$$

10. Likes to play so wild and recklessly that s/he might get hurt.

$$
\begin{array}{llllllll}
1 & 2 & 3 & 4 & 5 & 6 & 7 & \text { NA }
\end{array}
$$

11. Seems to be at ease with almost any person.

$\begin{array}{llllllll}1 & 2 & 3 & 4 & 5 & 6 & 7 & \text { NA }\end{array}$


12. Tends to run rather than walk from room to room.

$\begin{array}{llllllll}1 & 2 & 3 & 4 & 5 & 6 & 7 & \text { NA }\end{array}$

13. Notices it when parents are wearing new clothing.

$\begin{array}{llllllll}1 & 2 & 3 & 4 & 5 & 6 & 7 & \text { NA }\end{array}$

14. Has temper tantrums when s/he doesn't get what s/he wants.

$\begin{array}{llllllll}1 & 2 & 3 & 4 & 5 & 6 & 7 & \text { NA }\end{array}$

15. Gets very enthusiastic about the things s/he does

$\begin{array}{llllllll}1 & 2 & 3 & 4 & 5 & 6 & 7 & \text { NA }\end{array}$

16. When practicing an activity, has a hard time keeping her/his mind on it.

$\begin{array}{llllllll}1 & 2 & 3 & 4 & 5 & 6 & 7 & \text { NA }\end{array}$

17. Is afraid of burglars or the "boogie man."

$$
\begin{array}{llllllll}
1 & 2 & 3 & 4 & 5 & 6 & 7 & \text { NA }
\end{array}
$$

18. When outside, often sits quietly.

$$
\begin{array}{llllllll}
1 & 2 & 3 & 4 & 5 & 6 & 7 & \text { NA }
\end{array}
$$

19. Enjoys funny stories but usually doesn’t laugh at them.

$$
\begin{array}{llllllll}
1 & 2 & 3 & 4 & 5 & 6 & 7 & \text { NA }
\end{array}
$$

20. Tends to become sad if the family's plans don't work out.

$$
\begin{array}{llllllll}
1 & 2 & 3 & 4 & 5 & 6 & 7 & \text { NA }
\end{array}
$$

21. Will move from one task to another without completing any of them.

$$
\begin{array}{llllllll}
1 & 2 & 3 & 4 & 5 & 6 & 7 & \text { NA }
\end{array}
$$

22. Moves about actively (runs, climbs, jumps) when playing in the house.

$\begin{array}{llllllll}1 & 2 & 3 & 4 & 5 & 6 & 7 & \text { NA }\end{array}$


23. Is afraid of loud noises.

$\begin{array}{llllllll}1 & 2 & 3 & 4 & 5 & 6 & 7 & \text { NA }\end{array}$

24. Seems to listen to even quiet sounds.

$\begin{array}{llllllll}1 & 2 & 3 & 4 & 5 & 6 & 7 & \text { NA }\end{array}$

25. Has a hard time settling down after an exciting activity.

$\begin{array}{llllllll}1 & 2 & 3 & 4 & 5 & 6 & 7 & \mathrm{NA}\end{array}$

26. Enjoys taking warm baths.

$\begin{array}{llllllll}1 & 2 & 3 & 4 & 5 & 6 & 7 & \mathrm{NA}\end{array}$

27. Seems to feel depressed when unable to accomplish some task.

$\begin{array}{llllllll}1 & 2 & 3 & 4 & 5 & 6 & 7 & \text { NA }\end{array}$

28. Often rushes into new situations.

$\begin{array}{llllllll}1 & 2 & 3 & 4 & 5 & 6 & 7 & \text { NA }\end{array}$

29. Is quite upset by a little cut or bruise.

$\begin{array}{llllllll}1 & 2 & 3 & 4 & 5 & 6 & 7 & \text { NA }\end{array}$

30. Gets quite frustrated when prevented from doing something s/he wants to do.

$\begin{array}{llllllll}1 & 2 & 3 & 4 & 5 & 6 & 7 & \text { NA }\end{array}$

31. Becomes upset when loved relatives or friends are getting ready to leave following a visit.

$$
\begin{array}{llllllll}
1 & 2 & 3 & 4 & 5 & 6 & 7 & \text { NA }
\end{array}
$$

32. Comments when a parent has changed his/her appearance.

$$
\begin{array}{llllllll}
1 & 2 & 3 & 4 & 5 & 6 & 7 & \text { NA }
\end{array}
$$

33. Enjoys activities such as being chased, spun around by the arms, etc.

$$
\begin{array}{llllllll}
1 & 2 & 3 & 4 & 5 & 6 & 7 & \text { NA }
\end{array}
$$

34. When angry about something, s/he tends to stay upset for ten minutes or longer. 
$\begin{array}{llllllll}1 & 2 & 3 & 4 & 5 & 6 & 7 & \text { NA }\end{array}$

35. Is not afraid of the dark.

$\begin{array}{llllllll}1 & 2 & 3 & 4 & 5 & 6 & 7 & \text { NA }\end{array}$

36. Takes a long time in approaching new situations.

$$
\begin{array}{llllllll}
1 & 2 & 3 & 4 & 5 & 6 & 7 & \text { NA }
\end{array}
$$

37. Is sometimes shy even around people s/he has known a long time.

$$
\begin{array}{llllllll}
1 & 2 & 3 & 4 & 5 & 6 & 7 & \text { NA }
\end{array}
$$

38. Can wait before entering into new activities if s/he is asked to.

$$
\begin{array}{llllllll}
1 & 2 & 3 & 4 & 5 & 6 & 7 & \text { NA }
\end{array}
$$

39. Enjoys "snuggling up" next to a parent or babysitter.

$$
\begin{array}{llllllll}
1 & 2 & 3 & 4 & 5 & 6 & 7 & \text { NA }
\end{array}
$$

40. Gets angry when s/he can't find something s/he wants to play with.

$$
\begin{array}{llllllll}
1 & 2 & 3 & 4 & 5 & 6 & 7 & \text { NA }
\end{array}
$$

41. Is afraid of fire.

$$
\begin{array}{llllllll}
1 & 2 & 3 & 4 & 5 & 6 & 7 & \text { NA }
\end{array}
$$

42. Sometimes seems nervous when talking to adults s/he has just met.

$$
\begin{array}{llllllll}
1 & 2 & 3 & 4 & 5 & 6 & 7 & \text { NA }
\end{array}
$$

43. Is slow and unhurried in deciding what to do next.

$$
\begin{array}{llllllll}
1 & 2 & 3 & 4 & 5 & 6 & 7 & \text { NA }
\end{array}
$$

44. Changes from being upset to feeling much better within a few minutes.

$$
\begin{array}{llllllll}
1 & 2 & 3 & 4 & 5 & 6 & 7 & \mathrm{NA}
\end{array}
$$

45. Prepares for trips and outings by planning things s/he will need..

$$
\begin{array}{llllllll}
1 & 2 & 3 & 4 & 5 & 6 & 7 & \text { NA }
\end{array}
$$


46. Becomes very excited while planning for trips.

$\begin{array}{llllllll}1 & 2 & 3 & 4 & 5 & 6 & 7 & \text { NA }\end{array}$

47. Is quickly aware of some new item in the living room.

$\begin{array}{llllllll}1 & 2 & 3 & 4 & 5 & 6 & 7 & \text { NA }\end{array}$

48. Hardly ever laughs out loud during play with other children.

$\begin{array}{llllllll}1 & 2 & 3 & 4 & 5 & 6 & 7 & \text { NA }\end{array}$

49. Is not very upset at minor cuts or bruises.

$\begin{array}{llllllll}1 & 2 & 3 & 4 & 5 & 6 & 7 & \text { NA }\end{array}$

50. Prefers quiet activities to active games.

$\begin{array}{llllllll}1 & 2 & 3 & 4 & 5 & 6 & 7 & \text { NA }\end{array}$

51. Tends to say the first thing that comes to mind, without stopping to think about it.

$$
\begin{array}{llllllll}
1 & 2 & 3 & 4 & 5 & 6 & 7 & \text { NA }
\end{array}
$$

52. Acts shy around new people.

$\begin{array}{llllllll}1 & 2 & 3 & 4 & 5 & 6 & 7 & \text { NA }\end{array}$

53. Has trouble sitting still when s/he is told to (at movies, church, etc.).

$\begin{array}{llllllll}1 & 2 & 3 & 4 & 5 & 6 & 7 & \text { NA }\end{array}$

54. Rarely cries when s/he hears a sad story.

$\begin{array}{llllllll}1 & 2 & 3 & 4 & 5 & 6 & 7 & \text { NA }\end{array}$

55. Sometimes smiles or giggles playing by her/himself.

$\begin{array}{llllllll}1 & 2 & 3 & 4 & 5 & 6 & 7 & \text { NA }\end{array}$

56. Rarely becomes upset when watching a sad event in a TV show.

$\begin{array}{llllllll}1 & 2 & 3 & 4 & 5 & 6 & 7 & \text { NA }\end{array}$


57. Enjoys just being talked to.

$\begin{array}{llllllll}1 & 2 & 3 & 4 & 5 & 6 & 7 & \mathrm{NA}\end{array}$

58. Becomes very excited before an outing (e.g., picnic, party).

$\begin{array}{llllllll}1 & 2 & 3 & 4 & 5 & 6 & 7 & \text { NA }\end{array}$

59. If upset, cheers up quickly when s/he thinks about something else.

$$
\begin{array}{llllllll}
1 & 2 & 3 & 4 & 5 & 6 & 7 & \text { NA }
\end{array}
$$

60. Is comfortable asking other children to play.

$\begin{array}{llllllll}1 & 2 & 3 & 4 & 5 & 6 & 7 & \text { NA }\end{array}$

61. Rarely gets upset when told s/he has to go to bed.

$\begin{array}{llllllll}1 & 2 & 3 & 4 & 5 & 6 & 7 & \text { NA }\end{array}$

62. When drawing or coloring in a book, shows strong concentration.

$$
\begin{array}{llllllll}
1 & 2 & 3 & 4 & 5 & 6 & 7 & \text { NA }
\end{array}
$$

63. Is afraid of the dark.

$$
\begin{array}{llllllll}
1 & 2 & 3 & 4 & 5 & 6 & 7 & \text { NA }
\end{array}
$$

64. Is likely to cry when even a little bit hurt.

$$
\begin{array}{llllllll}
1 & 2 & 3 & 4 & 5 & 6 & 7 & \text { NA }
\end{array}
$$

65. Enjoys looking at picture books.

$$
\begin{array}{llllllll}
1 & 2 & 3 & 4 & 5 & 6 & 7 & \text { NA }
\end{array}
$$

66. Is easy to soothe when $\mathrm{s} / \mathrm{he}$ is upset.

$$
\begin{array}{llllllll}
1 & 2 & 3 & 4 & 5 & 6 & 7 & \mathrm{NA}
\end{array}
$$

67. Is good at following instructions.

$$
\begin{array}{llllllll}
1 & 2 & 3 & 4 & 5 & 6 & 7 & \text { NA }
\end{array}
$$

68. Is rarely frightened by "monsters" seen on TV or at movies. 


\section{$\begin{array}{llllllll}1 & 2 & 3 & 4 & 5 & 6 & 7 & \text { NA }\end{array}$}

69. Likes to go high and fast when pushed on a swing.

$\begin{array}{llllllll}1 & 2 & 3 & 4 & 5 & 6 & 7 & \text { NA }\end{array}$

70. Sometimes turns away shyly from new acquaintances.

$\begin{array}{llllllll}1 & 2 & 3 & 4 & 5 & 6 & 7 & \text { NA }\end{array}$

71. When building or putting something together, becomes very involved in what s/he is doing, and works for long periods.

$$
\begin{array}{llllllll}
1 & 2 & 3 & 4 & 5 & 6 & 7 & \text { NA }
\end{array}
$$

72. Likes being sung to.

$\begin{array}{llllllll}1 & 2 & 3 & 4 & 5 & 6 & 7 & \text { NA }\end{array}$

73. Approaches places s/he has been told are dangerous slowly and cautiously.

$\begin{array}{llllllll}1 & 2 & 3 & 4 & 5 & 6 & 7 & \text { NA }\end{array}$

74. Rarely becomes discouraged when s/he has trouble making something work.

$$
\begin{array}{llllllll}
1 & 2 & 3 & 4 & 5 & 6 & 7 & \text { NA }
\end{array}
$$

75. Is very difficult to soothe when s/he has become upset.

$$
\begin{array}{llllllll}
1 & 2 & 3 & 4 & 5 & 6 & 7 & \text { NA }
\end{array}
$$

76. Likes the sound of words, such as nursery rhymes.

$$
\begin{array}{llllllll}
1 & 2 & 3 & 4 & 5 & 6 & 7 & \text { NA }
\end{array}
$$

77. Smiles a lot at people s/he likes.

$$
\begin{array}{llllllll}
1 & 2 & 3 & 4 & 5 & 6 & 7 & \text { NA }
\end{array}
$$

78. Dislikes rough and rowdy games.

$$
\begin{array}{llllllll}
1 & 2 & 3 & 4 & 5 & 6 & 7 & \text { NA }
\end{array}
$$

79. Often laughs out loud in play with other children. 
$\begin{array}{llllllll}1 & 2 & 3 & 4 & 5 & 6 & 7 & \text { NA }\end{array}$

80. Rarely laughs aloud while watching TV or movie comedies.

$\begin{array}{llllllll}1 & 2 & 3 & 4 & 5 & 6 & 7 & \text { NA }\end{array}$

81. Can easily stop an activity when s/he is told "no."

$\begin{array}{llllllll}1 & 2 & 3 & 4 & 5 & 6 & 7 & \mathrm{NA}\end{array}$

82. Is among the last children to try out a new activity.

$\begin{array}{llllllll}1 & 2 & 3 & 4 & 5 & 6 & 7 & \mathrm{NA}\end{array}$

83. Doesn't usually notice odors such as perfume, smoke, cooking, etc.

$\begin{array}{llllllll}1 & 2 & 3 & 4 & 5 & 6 & 7 & \text { NA }\end{array}$

84. Is easily distracted when listening to a story.

$$
\begin{array}{llllllll}
1 & 2 & 3 & 4 & 5 & 6 & 7 & \text { NA }
\end{array}
$$

85. Is full of energy, even in the evening.

$\begin{array}{llllllll}1 & 2 & 3 & 4 & 5 & 6 & 7 & \text { NA }\end{array}$

86. Enjoys sitting on parent's lap.

$$
\begin{array}{llllllll}
1 & 2 & 3 & 4 & 5 & 6 & 7 & \text { NA }
\end{array}
$$

87. Gets angry when called in from play before s/he is ready to quit.

$$
\begin{array}{llllllll}
1 & 2 & 3 & 4 & 5 & 6 & 7 & \text { NA }
\end{array}
$$

88. Enjoys riding a tricycle or bicycle fast and recklessly.

$$
\begin{array}{llllllll}
1 & 2 & 3 & 4 & 5 & 6 & 7 & \text { NA }
\end{array}
$$

89. Sometimes becomes absorbed in a picture book and looks at it for a long time.

$$
\begin{array}{llllllll}
1 & 2 & 3 & 4 & 5 & 6 & 7 & \text { NA }
\end{array}
$$

90. Remains pretty calm about upcoming desserts like ice cream. 


$$
\begin{array}{llllllll}
1 & 2 & 3 & 4 & 5 & 6 & 7 & \text { NA }
\end{array}
$$

91. Hardly ever complains when ill with a cold.

$\begin{array}{llllllll}1 & 2 & 3 & 4 & 5 & 6 & 7 & \text { NA }\end{array}$

92. Looks forward to family outings, but does not get too excited about them.

$\begin{array}{llllllll}1 & 2 & 3 & 4 & 5 & 6 & 7 & \text { NA }\end{array}$

93. Likes to sit quietly and watch people do things.

$$
\begin{array}{llllllll}
1 & 2 & 3 & 4 & 5 & 6 & 7 & \text { NA }
\end{array}
$$

94. Enjoys gentle rhythmic activities, such as rocking or swaying.

$$
\begin{array}{llllllll}
1 & 2 & 3 & 4 & 5 & 6 & 7 & \mathrm{NA}
\end{array}
$$

Please check back to make sure you have completed all the pages of the questionnaire. Thank you very much for your help. 
Curriculum Vitae

Ying Dong

Dongy212@gmail.com

\section{Education}

M.A. West Virginia University. Morgantown, WV

2007-2010. Science of Art, with an emphasis in Elementary Education

M.A. West Virginia University. Morgantown, WV

2007-2010. Educational Psychology, with an emphasis in Child Development and Family Studies

\section{B.A. Yunnan University, Kunming, Yunnan, P.R. China}

1993-1997. Science of Art, with an emphasis in Information Science

\section{Experience}

August, 2009- May, 2010. West Virginia University. Morgantown, WV

Graduate Assistant. Department of Technology, Learning, and Culture

August, 2009- May, 2010. West Virginia University. Morgantown, WV

Graduate Student Representative. The Advisory Board of the Office for Diversity \& Global Initiatives, College of Human Resources and Education

2000-2009. Yunnan Institute of Medical Information. Kunming, Yunnan, P. R. China.

Full-time Editor, Journal Publishing House of Soft Science of Health

1997-2000. Kunming Kaiwah Plaza Hotel. Kunming, Yunnan, P. R. China.

Full-time administrator, Department of Archive

Selected Peer-Reviewed Journal Publications

Liu, G., Dong, Y., Study of Grammatical Evolution Based on Formal Grammar, Computers and Applied Chemistry, Vol. 23, No. 6, 2006, p.511-514 
Liu, G., Dong, Y., Design of Web Platform for Genome-Database Based on PHP, Computers and Applied Chemistry, Vol. 23, No. 12, 2006, p.1215-1218

Dong, Y., Research for Construction of Visual Library Based on Internet, Soft Science of Health, Vol. 17, May, 2003 (in Chinese)

Dong, Y., Commercializing and Marketing of Information, Journal of Informatics, Vol. 22, December, 2003 (in Chinese)

Dong, Y., Some Thoughts about Electric Files and Archive, Journal of Kunming Archive, Vol. 4, December, 2003 (in Chinese)

Dong, Y., Research for Construction of Visual Archives, Journal of Kunming Archive, Vol. 1, 2004 (in Chinese) 